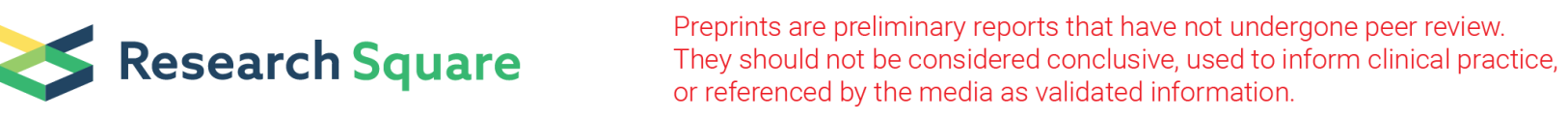

\title{
Investigating the Response of the Botswana High to El Niño Southern Oscillation using a Variable- Resolution Global Climate Model
}

Molulaqhooa Linda Maoyi ( $D$ myxmol001@myuct.ac.za )

University of Cape Town https://orcid.org/0000-0002-0176-098X

Babatunde Joseph Abiodun

University of Cape Town https://orcid.org/0000-0002-3878-0116

\section{Research Article}

Keywords: MPAS-Atmosphere, Botswana High, southern Africa, ENSO, Variable-Resolution Models, Global Climate Models

Posted Date: June 29th, 2021

DOI: https://doi.org/10.21203/rs.3.rs-461786/v1

License: (c) (i) This work is licensed under a Creative Commons Attribution 4.0 International License. Read Full License

Version of Record: A version of this preprint was published at Theoretical and Applied Climatology on January 13th, 2022. See the published version at https://doi.org/10.1007/s00704-021-03892-7. 


\section{Abstract}

The Botswana High is an important component of the regional atmospheric circulation during austral spring, summer and autumn. While the high tends to be stronger during El Niño and weaker during La Niña, its direct response to El Niño Southern Oscillation (ENSO) remains unknown. To that end, a variable resolution global climate model (Model Prediction Across Scales version 7, hereafter MPAS) is applied with relatively high resolution (48 km grid spacing) over southern Africa and a coarser resolution (240 km grid spacing) over the rest of the globe for the study period 1980-2010. The first model experiment uses observed SSTs everywhere during the study period, while the second experiment uses observed SSTs everywhere except over the Pacific Ocean, where monthly climatological SSTs are imposed. The model results were validated against satellite data (Global Precipitation Climatology Project, GPCP), reanalysis datasets (Climate Forecast System Reanalysis, CFSR; European Centre for Medium-Range Weather Forecasts version 5, ERA5). The results of the study show that the MPAS model gives a credible simulation of the temporal variability of the Botswana High, the seasonal rainfall and $500 \mathrm{hPa}$ geopotential heights over southern Africa. In the absence of ENSO forcing, the amplitude of the Botswana High variability reduces but the signal of the variability remains. Hence, this study shows that ENSO enhances the strength of the Botswana High but does not aid in the formation of the Botswana High.

\section{Introduction}

The Botswana High, a prominent feature in the mid-levels $(\sim 500 \mathrm{hPa})$ over southern Africa, is an important component of the regional atmospheric circulation during austral spring, summer and autumn (Reason 2016; Driver and Reason 2017). The high typically forms around August, shifting south as it strengthens throughout spring becoming stronger in the late summer (January, February and March). In April, the high moves northwards from its March position, weakens over the landmass and dissipates around May. It links its movement as it shifts south-eastwards to the movement of regions of high rainfall over the Congo basin and the ITCZ, which lie to its northeast (Driver and Reason 2017). The strengthening of the high is typically characterised by increased subsidence over southern Africa that suppresses moisture convergence and the development of tropical extratropical cloud bands (TTTs) and may lead to less rainfall. Conversely, the weakening of the high favours the development of TTTs, the main summer rainfall producing systems, and anomalous wet summers. According to Driver and Reason (2017), the Botswana Highs variability also affects the frequency of dry spells during summer (JFM), maximum surface temperatures, and maximum temperature extremes. These parameters strongly influence drought, which significantly impacts food supply as the people's livelihood highly depends on rain-fed agriculture. Considering this, a better understanding of the Botswana Highs variability may lead to a better seasonal forecasting of drought over southern Africa and a better response capacity. The aim of the present study is in that direction.

Several studies have been conducted to understand the summer variability of the Botswana High, some of which have identified the El Niño Southern Oscillation (ENSO) to be one major cause of the variability (Driver and Reason 2017; Reason 2018). In general, the high tends to intensify during El Niño associated 
summers over southern Africa and weaken during La Niña events; however, the magnitudes of the Botswana High anomalies are not necessarily proportional to the strength of ENSO events. For example, Driver and Reason (2017) showed that the anomaly in the high during the intense 1997/1998 El Niño event was less than the weaker 1986/1987 El Niño event. Furthermore, there have also been summers over southern Africa that were unusually wet or dry but did not coincide with an ENSO event but did correspond to significant anomalies in the Botswana High. As a result, gaining a better understanding of the Botswana High variability may provide useful information as well as another metric for monitoring and evaluating rainfall over the subcontinent. Despite that, we should note that previous studies have used analyses such as correlation and composite analyses in determining the relationship between ENSO and the Botswana High, which cannot determine cause-and-effect relationships. Therefore, it is unknown if the Botswana Highs variability is a response to ENSO. That is the motivation for this study.

This study presents a Global Climate Model (GCM) sensitivity experiment using Model for Prediction Across Scales (MPAS; Skamarock et al. 2012) to demonstrate the causal relationship between ENSO and the Botswana High. The MPAS model has been used in several sensitivity experiments (Davis 2016; Fowler et al. 2016; Zhao et al. 2016; Judt 2020). Zhao et al. (2016) used four different quasi-uniform resolution meshes $(30,60,120$ and $240 \mathrm{~km})$ and a variable-resolution mesh $(120-30 \mathrm{~km})$ in studying the impacts of resolution and physics (CAM4 vs CAM5) on the precipitation, clouds and large-scale circulation in an aquaplanet simulation. Using two configurations on MPAS, Davis (2016) compared a uniform $15 \mathrm{~km}$ mesh to a variable-resolution mesh $(60 \mathrm{~km}-15 \mathrm{~km})$ in simulating tropical cyclones in the eastern Pacific and found that the two configurations performed nearly identical to each other and performed comparably to the Global Forecasting System. Fowler et al. (2016) evaluated the performance of the Grell-Freitas parameterisation scheme using variable-resolution meshes, which varied between hydrostatic $(50 \mathrm{~km})$ and nonhydrostatic $(3 \mathrm{~km})$ scales and found that by increasing horizontal resolution, the subgrid-scale motions become increasingly resolved. Judt (2020) studied atmospheric predictability by using a set of twin experiments (Judt 2018; Zhang et al. 2007) and found that tropics have longer predictability than midlatitudes and polar regions.

This study investigates the response of Botswana High to the 1983, 1992, 1998 and 2010 El Niños and 1985, 1989, 2000 and 2008 La Niñas. Although this set does not include all ENSO events, we selected those years as they represent the strongest ENSO events between 1980 and 2010. We focus on the late summer season (JFM), when ENSO impacts are typically more significant and consistent than early summer (October to December) (Driver et al. 2017). For this investigation, we performed two experiments with the latest version of MPAS (MPAS version 7.0; hereafter, MPAS) model. The first experiment (i.e. control experiment, hereafter CTRL) uses observed SST forcing everywhere, while in the second experiment (i.e. idealised experiment, hereafter NoENSO), observed SSTs were replaced by monthly climatological SSTs in the Pacific Ocean. We replaced observed SSTS with monthly climatology to remove the influence of ENSO and assay Botswana High's response to ENSO. The paper is organised as follows: Sect. 2 describes the data used in the study and the methods. The results of the study are discussed in Sect. 3, while Sect. 4 presents the conclusion. 


\section{Data And Methodology \\ 2.1 Data}

We analysed observational, reanalysis and model simulation data for the study period 1980-2010. The observational data included monthly rainfall data obtained from the Global Precipitation Climatology Project Version 2.3 dataset (hereafter GPCP). The GPCP dataset has a resolution of $2.5^{\circ} \times 2.5^{\circ}$ grid resolution and is used to evaluate the model simulated rainfall over southern Africa. 6 hourly observed SSTs and sea-ice data were retrieved from the Climate Forecast System Reanalysis (CFSR). The CFSR data is provided by the National Centers for Environmental Prediction (NCEP) and is obtainable from https://rda.ucar.edu/datasets/ds093.1/. The SST dataset has a grid resolution of $0.31^{\circ} \mathrm{x} \sim 0.31^{\circ}$ and is used to force the model simulation and calculate the ENSO index.

The monthly geopotential height, with a horizontal resolution of $0.25^{\circ} \times 0.25^{\circ}$ and 37 levels, was obtained from the 5th generation European Centre for Medium-Range Weather Forecast reanalysis (Hereafter ERA5) data https://cds.climate.copernicus.eu and was used to evaluate how well the MPAS model simulates the seasonal characteristics of the $500 \mathrm{hPa}$ geopotential height over southern Africa as well the interannual variability of the Botswana High.

The monthly $500 \mathrm{hPa}$ geopotential height and rainfall data with a spatial resolution of $240 \mathrm{~km}$ and 41 vertical levels were obtained from the MPAS version 5.2 (MPAS5) simulation output of Maoyi and Abiodun (2021). The MPAS5 uniform grid output $(240 \mathrm{~km})$ was used to evaluate how well the MPAS variable-resolution grid ( $240 \mathrm{~km}$ globally and $48 \mathrm{~km}$ over Southern Africa) improves the climatic features over southern Africa and the interannual variability of the Botswana High.

\subsection{Model Description and Experiments}

The model utilised in this study is the most recent version of the Model for Prediction Across Scales version 7.0 model (MPAS), which is a fully compressible non-hydrostatic global climate model that utilises Voronoi tessellations (Du et al. 1999) to generate variable-resolution meshes. The variableresolution grid structure allows high-resolution areas to transition to lower resolution areas, avoiding boundary issues that plague conventional regional climate models.

MPAS uses Advanced Research WRF (ARW) model physics as well as an atmospheric fluid-flow dynamical core. The numerical schemes used in MPAS are similar to those used the in ARW model with the exception that ARW uses rectangular meshes and a hydrostatic vertical coordinate while the fully compressible non-hydrostatic equations in MPAS are derived in terms of a geometric-height vertical coordinate, and the solvers use a split-explicit time integration scheme which is described in Klemp et al. (2007). For meteorologically significant modes, the time-integration scheme employs a 3rd Order RungeKutta method and a large time step and a forward-backwards method with a smaller time step for acoustic modes. 
In the present study, the MPAS model grid is set to a variable resolution of $48 \mathrm{~km}$ over southern Africa and $240 \mathrm{~km}$ worldwide (Fig. 1). The variable-resolution grid contains 30210 grid cells and refines by a factor of 5 (from $240 \mathrm{~km}$ grid spacing to $48 \mathrm{~km}$ grid spacing), which satisfies the Caian-Geleyn condition of limiting the refinement factor to less than 8 in order to minimise pole-symmetric dilations (Caian and Geleyn 1997). The prevailing advantage of using variable-resolution grids is applying higher resolution over an area of interest without requiring substantial computational power as with uniform highresolution grids. The model simulation uses 41 vertical levels with an integration time step of 240 seconds and an output rate of daily data. The model topography was obtained by interpolating the U.S. Geological Survey (USGS) Global Multi-resolution Terrain Elevation Data (GMTED2010) dataset into the MPAS grid. A 32-year control integration and a set of SST perturbation experiments were performed in this study. The control integration (hereafter CTRL) runs from the 1 st of January 1979 till the 31 st of December 2010; however, the results from 1979 were discarded as spin-up and only data from 1980 till 2010 was considered. For the control run to give a more realistic simulation, the integration was configured to update with 6 hourly CFSR SST and sea-ice data. A series of August - April integrations with perturbed SST (hereafter NoENSO) were conducted for four El Niño $(1983,1992,1998$ and 2010) and four La Niña $(1985,1989,2000$ and 2008) years. In the 9-month integrations, the SST is the same as in the control run except that monthly climatological SSTs are imposed over the Pacific Ocean in order to remove the influence of ENSO. For each 9-month integration, 10 ensembles were carried out with slightly different initial conditions to represent internal atmospheric variability. The initial conditions are taken from the previous years' August 20th - 29th snapshots (restart files) of the control run.

\subsection{Methodology}

\subsubsection{Model Validation}

To evaluate the capability of MPAS in simulating the climatic features over southern Africa, we compared the simulated data (rainfall and $500 \mathrm{hPa}$ geopotential height) to observed, reanalysis and MPAS5 model data. In the evaluation, we used spatial correlation and root-mean-square error (RMSE) to measure the model's similarity with climatic patterns over southern Africa with respect to the observational and reanalysis datasets. We used $\mathrm{R}^{2}$ analysis to quantify the proportion of the Botswana High variance that ENSO predicts and Pearson correlation to assess the strength and direction between the MPAS simulation, MPAS5, reanalysis, and SST data.

\subsubsection{ENSO Quantification}

The ENSO index was quantified using the Ocean Niño Index, which is the most common index used to monitor ENSO. We calculated the ENSO index as a 3-month running mean of SST anomalies in the Niño 3.4 region $\left(5^{\circ} \mathrm{N}-5^{\circ} \mathrm{S}, 170^{\circ} \mathrm{W}-120^{\circ} \mathrm{W}\right)$. El Niño (La Niña) periods were defined when SSTs anomalies in the Niño 3.4 region are above (below) $+0.5(-0.5)$ for five consecutive months. For this study, the ENSO index was calculated using CFRS SST data for the period 1980-2010.

\subsubsection{Identification of Botswana High}


To identify the Botswana High feature, an EOF analysis of the $500 \mathrm{hPa}$ geopotential height was performed over southern Africa on the ERA5 reanalysis and the monthly model-simulated data between 1980 and 2010. The analysis was performed for the late summer (JFM) season. The Botswana High typically lies on the southern portion of the continent, and therefore the region lying between $10^{\circ} \mathrm{E}$ to $40^{\circ} \mathrm{E}$ and from the equator to $33^{\circ} \mathrm{S}$ was chosen to exclude the influence of oceans and their anticyclones. Additionally, we also quantified the Botswana High index using a spatial average of $500 \mathrm{hPa}$ geopotential height anomalies over the Botswana High core region $\left(5^{\circ}-22^{\circ} \mathrm{E} ; 20^{\circ}-25^{\circ} \mathrm{S}\right)$ in order to verify whether the EOF analysis is physically related to the temporal variability of the $500 \mathrm{hPa}$ geopotential height over the Botswana High core region.

\subsubsection{Assessing the response of Botswana High to ENSO}

To assess the response of the Botswana High to ENSO, two model experiments are conducted. The first experiment uses observed SSTs everywhere (CTRL), while the second experiment uses observed SST everywhere except over the Pacific Ocean, where monthly climatological SSTs are used. By prescribing monthly climatological SSTs over the Pacific, we essentially removed the ENSO signal and therefore referred to this experiment as NoENSO. These experiments are aimed to understand better the sensitivity of global and regional climatic features to ENSO events and how those impact the Botswana High.

\section{Results And Discussion}

\subsection{Relationship between the Botswana High and ENSO}

Figure 3a shows a strong association in the interannual variability of the Botswana High and ENSO. The MPAS, MPAS5 and ERA5 show a high correlation between Botswana Highs and ENSO $(r=0.84, r=0.81$ and $r=0.89$, respectively). In addition, the Botswana High in MPAS shows a higher correlation with one in ERA5 $(r=0.89)$ as compared to MPAS5 Botswana High $(r=0.87)$. These results show that the MPAS model improves the simulation of the interannual variability of the Botswana High, although by a small margin. Both models and reanalysis indicate the strongest Botswana Highs during the strong El Niño years (1983, 1998 and 2010), while the weakest Botswana Highs occurred in La Niña years (1985, 1989, and 2000) (Fig. 3a). This is in agreement with previous studies by Driver and Reason (2017). However, the relationship is not strictly linear as there are cases where the intensity of ENSO is not proportional to the intensity of the Botswana High (e.g. El Niño 1983 vs El Niño 1998). Kao and Yu (2009) showed that the nonlinear relationship could be explained by the internal variability of ENSO SST anomalies within the Pacific Ocean, creating different ENSO patterns. Furthermore, Johnson (2013) and Gore et al. (2019) identified eight ENSO SST patterns over the Pacific Ocean (four El Niño patterns and four La Niña patterns) which might impact the strength of the Botswana High differently.

Figure $3 \mathrm{~b}$ shows a scatter plot between the Botswana High and ENSO. As mentioned above, there seems to exist a quasi-linear relationship between the Botswana High and ENSO. At a 95\% confidence limit, the adjusted $\mathrm{R}^{2}$ values indicate that ENSO explains about $70 \%, 65 \%$, and $79 \%$ of Botswana High variability in 
the MPAS, MPAS5 and ERA5 datasets respectively. Again, the MPAS model improves the relationship between Botswana High and ENSO (70\%) as compared to MPAS5 (65\%). Given the strong association between the Botswana High and ENSO, the question then arises as to whether the Botswana High is a result of forcing from ENSO. To address this, the response of the Botswana High to the removal of ENSO forcing is discussed in Sect. 3.3.

\subsection{Composite Anomalies over Southern Africa}

We evaluate the MPAS simulation over southern Africa by comparing it with GPCP observation, ERA5 reanalysis and MPAS5 model data (Figs. 4 and 5). The validation focuses on the spatial distribution of rainfall (Fig. 4) and the 500 hPa geopotential height (Fig. 5) in JFM of El Niño years (1983, 1992, 1998; and 2010) and La Niña Years $(1985,1989,2000$, and 2008). Figure 4 shows that MPAS simulates well spatial distribution of rainfall over southern Africa, except that the simulation generally has a better agreement with GPCP during El Niño years composite $(r=0.85$; RMSE $=1.67)$ than during La Niña years composite $(r=0.80$; RMSE = 2.12). During the El Niño years, the model captures well the band of maximum rainfall over the tropics (associated with the South Indian Convergence Zone, SICZ) with a wet bias of about $\pm 1 \mathrm{~mm}$ day $^{-1}$. It also reproduces well the rainfall over the eastern parts of the continent and areas of minimum rainfall over the central and western parts of South Africa and Namibia. Over Madagascar, the model fails to capture the local maximum rainfall as in GPCP. This lack of maximum rainfall over Madagascar may be attributed to the overestimation of deep convection over the Mozambique Channel (MC) area (Figs. 4b, 4f, 4j, 4n and 4r), which may suppress convection over adjacent areas leading to the inability of MPAS to stimulate the local maximum rainfall over Madagascar. Despite that, the MPAS composite $(r=0.85$; RMSE $=1.67)$ shows that the MPAS variable-resolution generally improves the simulation of rainfall over the region as compared to the uniform resolution MPAS5 composite $(r=0.83$; RMSE $=1.78)$ during El Niño years.

During the La Niña years, the MPAS model underestimates the summer rainfall over the eastern and central parts of Botswana, Mozambique and South Africa (by about $3 \mathrm{~mm}$ day $^{-1}$ ). This may be attributed to the overestimated deep convection extending farther south of the MC (Figs. 4d, 4h, 4l, 4p, and 4t), leading to the suppression of convective rainfall and a dry bias over the eastern and central parts of the southern African continent. Furthermore, the overestimation of deep convection over the MC is greater in the MPAS variable-grid than MPAS5 uniform-grid during La Niña. This reduces the accuracy of the MPAS in simulating the regional rainfall as compared to MPAS5. This result is consistent with Maoyi et al. (2017) and Driver et al. (2018), who noted a similar wet bias over the MC using a $50 \mathrm{~km}$ stretched-grid GCM (called CAM-EULAG). The wet bias could be due to the convective parameterisation in the model, which might be too sensitive to the warm boundary layer over the region. Another cause for this wet bias could be the horizontal resolution sensitivity of moist physics as highlighted by Williamson (2008) or the parameterisation time step in the model simulation as indicated by Williamson and Olson (2003).

MPAS shows good agreement with ERA5 on the spatial pattern of the $500 \mathrm{hPa}$ geopotential height during El Niño years composite $(r=0.96$; RMSE $=10.08)$ and La Niña years composite $(r=0.96$ RMSE $=7.63)$. In 
general, both the MPAS and reanalysis show higher values of the $500 \mathrm{hPa}$ geopotential height during El Niño years and Lower values during La Niña years, suggesting that El Niño (La Niña) summers may be the driving force in the strengthening (weakening) of the $500 \mathrm{hPa}$ geopotential height over southern Africa, which may lead to the strengthening (weakening) of the Botswana High. This result is in agreement with previous studies by Reason (2016) and Driver and Reason (2017), who also found that the high is always stronger (weaker) during El Niño (La Niña) summers. Furthermore, the strong spatial correlations $(r>0.9)$ indicate that the model has adequate skill in reproducing the dominating features of the $500 \mathrm{hPa}$ geopotential height over southern Africa but with some discrepancies. For instance, the model shows enhanced geopotential heights in the subtropics and lower anomalies poleward of $30^{\circ} \mathrm{S}$ as in ERA5. In addition to that, the model captures the local maximum geopotential height pattern over southern Africa (which is reminiscent of the Botswana High) as in ERA5 (e.g. Figures 5a, 5e, 5i, 5m, 5q). Despite the higher resolution of MPAS variable-grid simulation (48 km) than the MPAS5 uniform-grid simulation $(240 \mathrm{~km})$ over southern Africa, MPAS results do not seem to always improve on that of MPAS5 as shown by the correlation and RMSE. While MPAS simulation outperforms the MPAS5 simulation in some years (i.e. 1992, 2010, 1989 and 2008), the opposite is true in other years $(1983,1998$, 1985 and 2000). Several factors could make the higher resolution MPAS simulation not always outperform the coarser resolution MPAS5 simulation. For example, both models use different land-use and topography data, which may impact results over high lying regions over southern Africa. Another reason could be the difference in the physics scheme between MPAS (WRF v4.0.3 physics) and MPAS5 (WRF v3.8.1 physics), which might have their strengths and weaknesses over southern Africa.

\subsection{Sensitivity Experiments}

\subsubsection{The response of the Botswana High to the removal of ENSO forcing}

Figure 6 shows the interannual variability of the Botswana High in CTRL and NoENSO for the EOF analysis (Fig. 6a) and spatial average analysis (Fig. 6b). The time series associated with the EOF Botswana High index (Fig. 6a) shows good similarity with the spatial average Botswana High index. This result indicates that the EOF Botswana High is physically related to the temporal variability of the 500 $\mathrm{hPa}$ geopotential height over the Botswana High core region. In light of this, the impact of ENSO on the temporal variability of the Botswana High is evident. In general, NoENSO shows that with the removal of the ENSO forcing (El Niño or La Niña), the amplitude of variability in Botswana High reduces; however, the signal of the Botswana High variability still remains. This indicates that the Botswana High modes are independent of ENSO forcing while the magnitude of the variability is enhanced during ENSO events. Figure 6 also suggests that there are cases when ENSO forcing may alter the signs of the Botswana High mode, either from + ve phase to -ve phase (as in 1992) or from + ve phase to -ve phase (as in 2008). This may be due to the internal variability of ENSO SST anomalies within the Pacific Ocean, creating different ENSO flavours that may impact the Botswana High distinctively. 
The $500 \mathrm{hPa}$ geopotential height composites show good agreement with the Botswana High's interannual variability during El Niño Years (Figs. 7a and 8a). At regional scale (over southern Africa), there is an overall decrease in the $500 \mathrm{hPa}$ geopotential height over southern Africa (Figs. 7a, 7c, 7e, 7g and 7i) which is consistent with the decrease in the interannual variability of the Botswana High index in 1983, 1992, 1998 and 2010; however, the largest decrease is over the northeastern parts of the southern African region, which is typically an area of high precipitation associated with the SICZ. Basically, the removal of El Niño influence leads to increased convection over the SICZ area leading to increased precipitation over northern Madagascar, Mozambique Channel, and much of the northeastern parts of the subcontinent. At global scale (Figs. 8a, 8c, 8e, 8g and 8i), all El Niño years $(1983,1992,1998,2010)$ show that with the removal El Niño event, there is a decrease in the $500 \mathrm{hPa}$ geopotential height over the tropics and an increase in the subtropics. This response represents a weakening of the Hadley circulation (Cook 2000), and it is generally known from modelling and observational studies (Oort and Yienger 1996; Roechner et al. 1996). In addition to that, this decrease in the $500 \mathrm{hPa}$ geopotential height over the tropics leads to a reduction in subsidence in the $500 \mathrm{hPa}$ pressure level over southern Africa (Figs. 7a, 7c, 7e, 7g and 7i), which in turn reduces the strength of the Botswana High as seen in Fig. 6.

La Niña composites (Fig. 7b and 8b) show an opposite pattern in the $500 \mathrm{hPa}$ geopotential heights compared to El Niño Composites. The regional circulation anomalies show an increase in subsidence over the region, especially over the Mozambique Channel, northern Mozambique and northern Madagascar (Figs. 7b, 7d, 7f, 7h and 7j). This anomalous increase in subsidence over the SICZ area may inhibit convection, increase temperatures, weaken the SICZ and lead to decreased precipitation. Reason (2016) attributed the formation of the Botswana High to heat released by tropical regions of high precipitation near the SICZ area. In light of this, the anomalous increase in subsidence and temperature over the SICZ may lead to the formation and strengthening of the Botswana High as Reason (2016) stated. However, a model experiment similar to Lenters and Cook (1997) is required to prove the veracity of the results, which is beyond the scope of this work.

Globally, there is an overall increase in the $500 \mathrm{hPa}$ geopotential height (NoENSO minus CTRL) over the tropics and a decrease over parts of the subtropics (Figs. 8b, 8d, 8f, 8h and 8j). This pattern represents the strengthening of the Hadley circulation (Cook 2000). This increase in the $500 \mathrm{hPa}$ geopotential height leads to an increase in subsidence over southern Africa, strengthening the Botswana High. The years 1985 and 1989 indicate a large increase in the $500 \mathrm{hPa}$ geopotential height in the northeastern regions of southern Africa, which are the same years where there was the highest increase in the Botswana High strength due to the absence of La Niña (see Fig. 6). This result implies that the Botswana High strength is sensitive to subsidence over this area during La Niña summers.

\subsubsection{Atmospheric dynamics associated with El Niño}

The difference in the $200 \mathrm{hPa}$ velocity potential between NoENSO and CTRL years show an upper tropospheric divergence (negative velocity potential) over the Indian and Western Pacific Ocean (Figs. 9a, $9 \mathrm{c}, 9 \mathrm{e}, 9 \mathrm{~g}$ and $9 \mathrm{i})$. This upper-level divergence is more pronounced over the northwest pacific and maritime continent, which coincides with deep convection from the warmer SSTs in the region. In 
contrast, there is a strong upper tropospheric convergence (positive velocity potential) over the eastern Pacific and South America, which coincides with cooler SSTs over that region. This convergencedivergence pattern across the Pacific is a reverse pattern of normal El Niño years and similar to a typical La Niña pattern. In normal El Niño years, the upper-level divergence is located over the eastern Pacific and South America, whilst the upper-level convergence is typically located over the western Pacific and maritime continent, including Australia. This normal pattern indicates a weakening of the Walker Circulation, which is typical during El Niño years (Reason and Jagadheesha 2005, Ashok et al. 2007, Yuan et al. 2014, Gore et al. 2019). Therefore, the reverse pattern, which is the difference between NoENSO and CTRL, indicates that the Walker Circulation will strengthen in the absence of El Niño. 1983 and 1998 show the most strengthening of the Walker Circulation as they were the strongest El Niño years in the study period. The southern African continent generally shows divergent flow, which may strengthen the SICZ and aid in the formation of tropical temperate troughs (Tyson and Preston-Whyte 2000) while weakening the strength of the Botswana High.

Figures 10a, 10c, 10e, 10g, and 10i show the difference between NoENSO and CTRL in the $200 \mathrm{hPa}$ eddy stream function for each El Niño year, highlighting the large-scale stationary wave response. Taking the difference filters out the zonal mean response and only shows the difference in the wave response. All El Niño years show a strengthening of the cyclonic flow in the upper troposphere over the central and eastern Pacific Ocean, associated with the intensity of cooling of SSTs in the region. The strong ENSO event of 1998 generated the strongest anomalies, which indicate that the SST cooling was more intense during that year while the cyclonic flow extended as far as the western Pacific as in 2010. On the contrary,

the South Atlantic and South Indian ocean show an increase in the upper tropospheric anticyclonic flow, indicating the warming of SSTs in the region. This warming of the two ocean basins may increase convergence over the southern African continent, leading to an overall weakening of subsidence in the $500 \mathrm{hPa}$ level as in Fig. 7, thus reducing the Botswana High's strength.

\subsubsection{Atmospheric dynamics associated with La Niña}

Figures $9 \mathrm{~b}, 9 \mathrm{~d}, 9 \mathrm{f}, 9 \mathrm{~h}$, and $9 \mathrm{j}$ show changes in the upper tropospheric divergence flow between NoENSO and CTRL. 1985, 1989 and 2008 show upper tropospheric divergence over much of the central and eastern Pacific and over much of the Atlantic Ocean, which coincides with deep convection from warmer SSTs. Contrary to that, there is an upper-level convergence (positive velocity potential) over much of the Indian Ocean, including Australia and the maritime continent, which corresponds to colder SSTs. This upper-level convergence over the Indian Ocean may result in a north-eastward shift of the SICZ (Cook 2001) and tropical temperate troughs (Tyson and Preston-Whyte 2000), strengthening drier conditions over southern Africa. This convergence-divergence pattern is reminiscent of the weakening of the Walker Circulation (Gore et al. 2019) and typically takes place during El Niño events. In general, the weakening of La Niña events will lead to an El Niño type of response in the atmosphere and vice-versa. The year 2000 showed a similar pattern with other La Niña years, except for a weak convergence over the Pacific. 1985 and 1989 had the highest velocity potential over southern Africa's northeast regions, which corresponds to the increase in subsidence over the region due to cooler SSTs. This corresponds well to the increase in 
the $500 \mathrm{hPa}$ geopotential height as in Fig. $8 \mathrm{~d}$ and $8 \mathrm{f}$ and the larger strengthening of the Botswana High $(1985,1989)$ as in Fig. 6 as compared to other La Niña Botswana High years $(2000,2008)$.

The difference in the eddy stream function at $200 \mathrm{hPa}$ (NoENSO minus CTRL) shows anticyclones over the eastern and western Pacific Ocean (Figs. 10b, 10d, 10f, 10h, and 10j). These anticyclones are characteristic of a Gill-Matsuno type response which is imminent due to the warming of Pacific Ocean SSTs (Cook 2001, Wilson et al. 2014, Gore et al. 2019). This increase in the strength of anticyclones leads to a reduction in the cyclonic flow over the Pacific Ocean and the weakening of the Walker Circulation. All La Niña years indicate an increase in the cyclonic flow over the southern parts of South America, Africa, the Atlantic Ocean and the Indian Ocean. This anomalous cyclonic flow in the upper troposphere indicates cooling SSTs over the region and may increase subsidence over southern Africa, thus strengthening the Botswana High.

\section{Conclusions}

Previous studies have shown a strong relationship between ENSO and the Botswana High (Reason 2016; Driver and Reason 2017; Maoyi and Abiodun 2021); however, the studies applied correlation and composite analysis, which cannot determine cause and effect in the relationship. In light of that, the present study investigated the Botswana High response to ENSO using a variable-resolution GCM (MPAS) to better understand the relationship between the Botswana High and ENSO. Two experiments were performed. The first experiment used observed SST everywhere (control experiment, CTRL), while the second experiment used observed SSTs everywhere except over the Pacific Ocean, where monthly climatological SSTs were used (NoENSO experiment). The capability of MPAS in simulating the climatic features over southern Africa and the temporal variability of the Botswana High were evaluated by comparing the models' historical simulations (CTRL, 1980-2010) with GPCP observation, ERA5 reanalysis and MPAS5 model data. The results of the study can be summarised as follows:

- The MPAS variable-resolution simulation reproduced the interannual variability of the Botswana High as in the ERA5 reanalysis. In all datasets, the Botswana High variability shows a strong link with ENSO ( $r>0.8)$ and suggests a quasi-linear relationship between the Botswana High and ENSO.

- MPAS generally captures the summer (JFM) climatic variables over southern Africa during El Niño and La Niña years, although with some biases across the region. However, in most cases, the results are comparable with GPCP observation and ERA5 reanalysis.

- Sensitivity experiments show that the Botswana High mode is independent of ENSO, but the amplitude of the modes amplify during ENSO events.

- The removal of the El Niño forcing strengthens the Walker Circulation and results in upper-level divergence $(200 \mathrm{hPa})$ over southern Africa. This upper-level divergence weakens the $500 \mathrm{hPa}$ geopotential height over the region resulting in a weak Botswana High. The opposite is true with the removal of the La Niña signal. 
The results of this study affirm the idea that ENSO fuels the Botswana High variability, but the formation of the Botswana High is independent of ENSO. To that end, more model experiments are still needed to establish the formation mechanisms of the summertime Botswana High. Reason (2016) suggested that the Botswana High could form as a response to the heat released by tropical regions of high precipitation located to their northeast. In the southern Africa region, this region is located near the SICZ. Therefore, future studies may apply the MPAS model to study the response of the Botswana High to condensational heating from the SICZ. Another area of study that requires attention could be on the overestimation of rainfall over the MC in the MPAS model, which causes a dry bias over the southern Africa region, especially during La Niña. Using variable-resolution models, Williams (2008) showed that precipitation is highly sensitive to the parameterisation time step and horizontal resolution and suggested when resolution increases, the parameterisation time step must be decreased. Therefore, potential work following from this study would consider the impact of the parameterisation timestep with respect to horizontal resolution, improving rainfall and Botswana High simulation over the region.

\section{Declarations}

Funding: This project was supported with grants from the UCT PhD Staff Bursary.

Conflicts of interest/Competing interests: Both authors declare that there is no conflict of interest and no competing interests.

Availability of data and material: All the data and materials used in this study can be freely made available on request.

Code availability: All the codes used in the study can be made available on request.

Authors' contributions: Both authors contributed to the study conception and methodology. Material preparation, data collection and analysis were performed by the first author under the supervision of the second author. The first draft of the manuscript was written by the first author and the second author was responsible for reviewing and editing previous versions of the manuscript. All authors read and approved the final manuscript.

Ethics Approval: Not applicable.

Consent to participate: Not applicable.

Consent for publication: Not applicable.

\section{References}

1. Ashok K, Behera SK, Rao SA, Weng H, Yamagata T (2007) El Niño Modoki and its possible teleconnection. J Geophys Res 112 (C11007). https://doi.org/10.1029/2006JC003798 
2. Caian M, Geleyn JF (1997) Some limits to the variable-mesh solution and comparison with the nested-lam solution. QJR Meteorol Soc 123(539):743-766. https://doi.org/10.1002/qj.49712353911

3. Cook KH (2000) The South Indian Convergence Zone and Interannual Rainfall Variability over Southern Africa. J Climate 13(21):3789-3804. https://doi.org/10.1175/15200442(2000)013\%3C3789:TSICZA\%3E2.0.CO;2

4. Cook KH (2001) A Southern Hemisphere Wave Response to ENSO with Implications for Southern Africa Precipitation. J Atmo Sci 58(15):2146-2162. https://doi.org/10.1175/15200469(2001)058\%3C2146:ASHWRT\%3E2.0.CO;2

5. Davis CA, Ahijevych DA, Wang W, Skamarock WC (2016) Evaluating Medium-Range Tropical Cyclone Forecasts in Uniform- and Variable-Resolution Global Models. Mon Wea Rev. 144(11):4141-4160. https://doi.org/10.1175/MWR-D-16-0021.1

6. Driver P, Abiodun B, Reason CJC (2018) Modelling the precipitation response over southern Africa to the 2009-2010 El Niño using a stretched grid global atmospheric model. Clim Dyn 52:3929-3949. https://doi.org/10.1007/s00382-018-4362-5

7. Driver P, Reason CJC (2017) Variability in the Botswana High and its relationships with rainfall and temperature characteristics over southern Africa. Int J Climatol 37: 570-581. https://doi.org/10.1002/joc.5022

8. Du Q, Faber V, Gunzburger M (1999) Centroidal Voronoi Tessellations: Applications and Algorithms. SIAM Review 41(4):637-676. https://doi.org/10.1137/S0036144599352836

9. Fowler LD, Skamarock WC, Grell GA, Freitas SR, Duda MG (2016) Analyzing the Grell-Freitas Convection Scheme from Hydrostatic to Nonhydrostatic Scales within a Global Model. Mon Wea Rev 144(6):2285-2306. https://doi.org/10.1175/MWR-D-15-0311.1

10. Gore M, Abiodun BJ, Kucharski F (2019) Understanding the influence of ENSO patterns on drought over southern Africa using SPEEDY. Clim Dyn 54:307-327. https://doi.org/10.1007/s00382-01905002-w

11. Johnson NC (2013) How many ENSO flavors can we distinguish? J Climate 26(13):4816-4827. https://doi.org/10.1175/JCLI-D-12-00649.1

12. Judt $F$ (2018) Insights into atmospheric predictability through global convection-permitting model simulations. J Atmo Sci 75:1477-1497. https://doi.org/10.1175/JAS-D-17-0343.1.

13. Judt $F$ (2020) Atmospheric predictability of the tropics, middle latitudes, and polar regions explored through global storm-resolving simulations. J Atmo Sci 77(1): 257276. https://doi.org/10.1175/JAS-D-19-0116.1

14. Kao H, Yu J (2009) Contrasting Eastern-Pacific and Central-Pacific Types of ENSO. J Climate 22(3):615-632. https://doi.org/10.1175/2008JCLI2309.1

15. Klemp JB, Skamarock WC, Dudhia J (2007) Conservative Split-Explicit Time Integration Methods for the Compressible Nonhydrostatic Equations. Mon Wea Rev 135(8):2897-2913. https://doi.org/10.1175/MWR3440.1 
16. Lenters JD, Cook KH (1997) On the Origin of the Bolivian High and Related Circulation Features of the South American Climate. J Atmo Sci 54(5):656-678. https://doi.org/10.1175/15200469(1997)054\%3C0656:OTOOTB\%3E2.0.C0;2

17. Maoyi ML, Abiodun BJ, Prusa JM, Veitch JJ (2018) Simulating the characteristics of tropical cyclones over the South West Indian Ocean using a Stretched-Grid Global Climate Model. Clim Dyn 50:1581-1596. https://doi.org/10.1007/s00382-017-3706-x

18. Maoyi ML, Abiodun BJ (2021) How Well Does MPAS-Atmosphere Simulate the Characteristics of the Botswana High? Research Square PREPRINT (Version 1). https://doi.org/10.21203/rs.3.rs$381126 / v 1$

19. Oort AH, Yienger JJ (1996) Observed Interannual Variability in the Hadley Circulation and Its Connection to ENSO. J Climate 9(11):2751-2767. https://doi.org/10.1175/15200442(1996)009\%3C2751:OIVITH\%3E2.0.CO;2

20. Reason CJC (2016) The Bolivian, Botswana, and Bilybara Highs and Southern Hemisphere drought/floods. Geophys Res Lett 43 1280- 1286. https://doi.org/10.1002/2015GL067228

21. Reason CJC, Jagadheesha D (2005) A model investigation of recent ENSO impacts over southern Africa. Meteorol Atmos Phys 89:181-205. https://doi.org/10.1007/s00703-005-0128-9

22. Roeckner E, Oberhuber JM, Bacher A, Christoph M, Kirchner I (1996) ENSO variability and the atmospheric response in a global coupled atmosphere-ocean GCM. Clim Dyn 12:737-754. https://doi.org/10.1007/s003820050140

23. Skamarock WC, Klemp JB, Duda MG, Fowler LD, Park S, Ringler TD (2012) A Multiscale Nonhydrostatic Atmospheric Model Using Centroidal Voronoi Tesselations and C-Grid Staggering. Mon Wea Rev 140(9):3090-3105. https://doi.org/10.1175/MWR-D-11-00215.1

24. Tyson PD, Preston-Whyte RA (2000) Weather and climate of southern Africa. Oxford University Press.

25. Williamson DL (2008) Convergence of aqua-planet simulations with increasing resolution in the Community Atmospheric Model, Version 3. Tellus A: Dynamic Meteorology and Oceanography 60(5):848-862. https://doi.org/10.1111/j.1600-0870.2008.00339.x

26. Williamson DL, Olson JG (2003) Dependence of aqua-planet simulations on time step. QJR Meteorol Soc 129: 2049-2064. https://doi.org/10.1256/qj.02.62

27. Wilson AB, Bromwich DH, Hines KM, Wang S (2014) El Niño Flavors and Their Simulated Impacts on Atmospheric Circulation in the High Southern Latitudes. J Climate 27(23):8934-8955. https://doi.org/10.1175/JCLI-D-14-00296.1

28. Yuan C, Tozuka T, Landman WA, Yamagata T (2014) Dynamical seasonal prediction of Southern African summer precipitation. Clim Dyn 42(11-12):3357-3374. https://doi.org/10.1007/s00382-0131923-5

29. Zhang F, Bei N, Rotunno R, Snyder C, Epifanio CC (2007) Mesoscale Predictability of Moist Baroclinic Waves: Convection-Permitting Experiments and Multistage Error Growth Dynamics. J Atmo Sci 64(10):3579-3594. https://doi.org/10.1175/JAS4028.1 
30. Zhao C, Leung LR, Park SH, Hagos S, Lu J, Sakaguchi K, Yoon J, Harrop BE, Skamarock W, Duda MG (2016) Exploring the impacts of physics and resolution on aqua-planet simulations from a nonhydrostatic global variable-resolution modeling framework. J Adv Model Earth Syst 8(4):17511768. https://doi.org/10.1002/2016MS000727

\section{Figures}

(a)

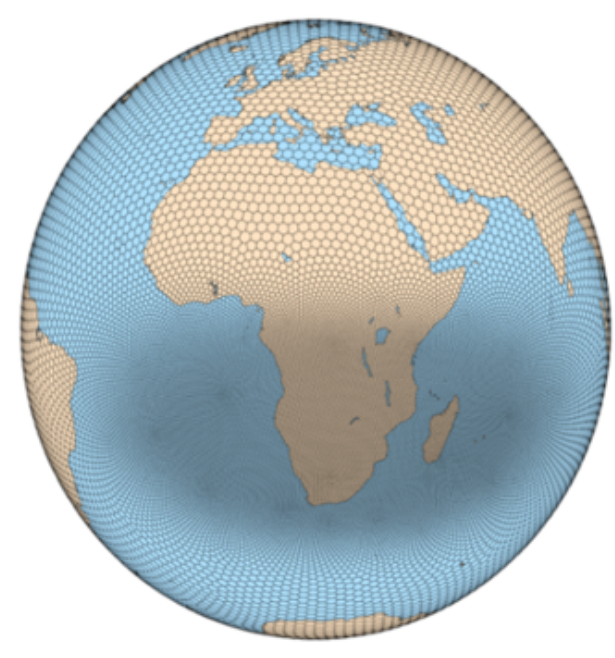

(b)

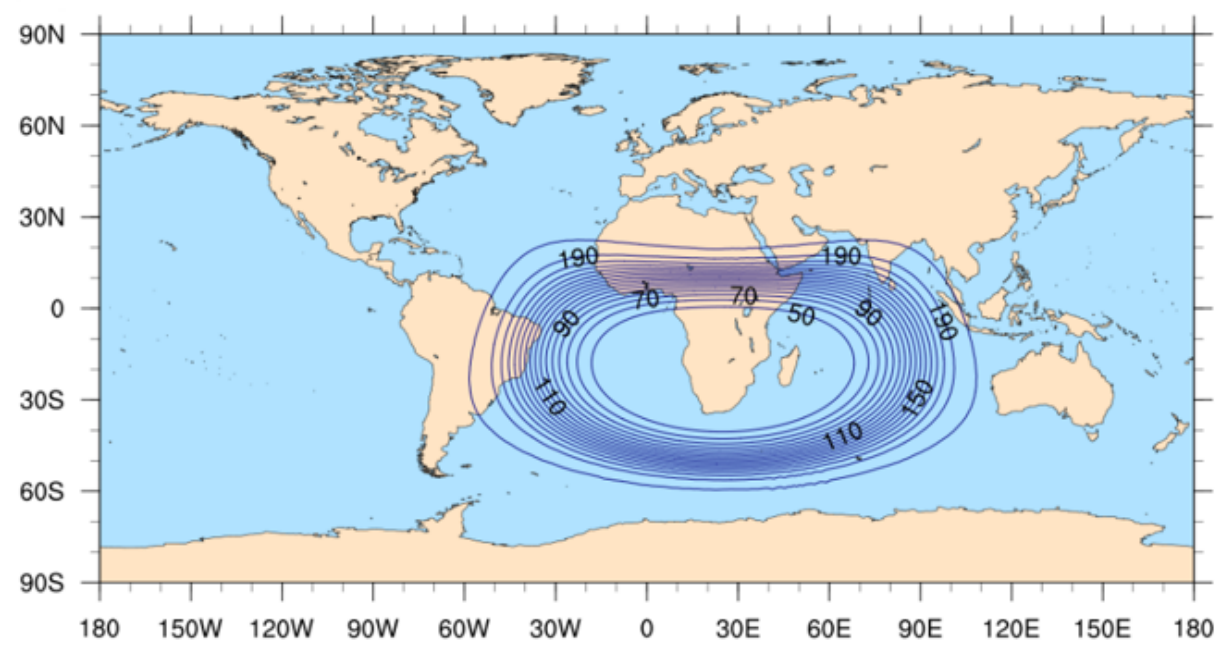

Figure 1

The configuration of MPAS variable-resolution mesh used in the study, featuring the highest resolution (48 km) over southern Africa and lower resolution $(240 \mathrm{~km})$ over much of the globe. The contours on (b) show the resolution from $50 \mathrm{~km}$ to $200 \mathrm{~km}$ in increments of $10 \mathrm{~km}$ 


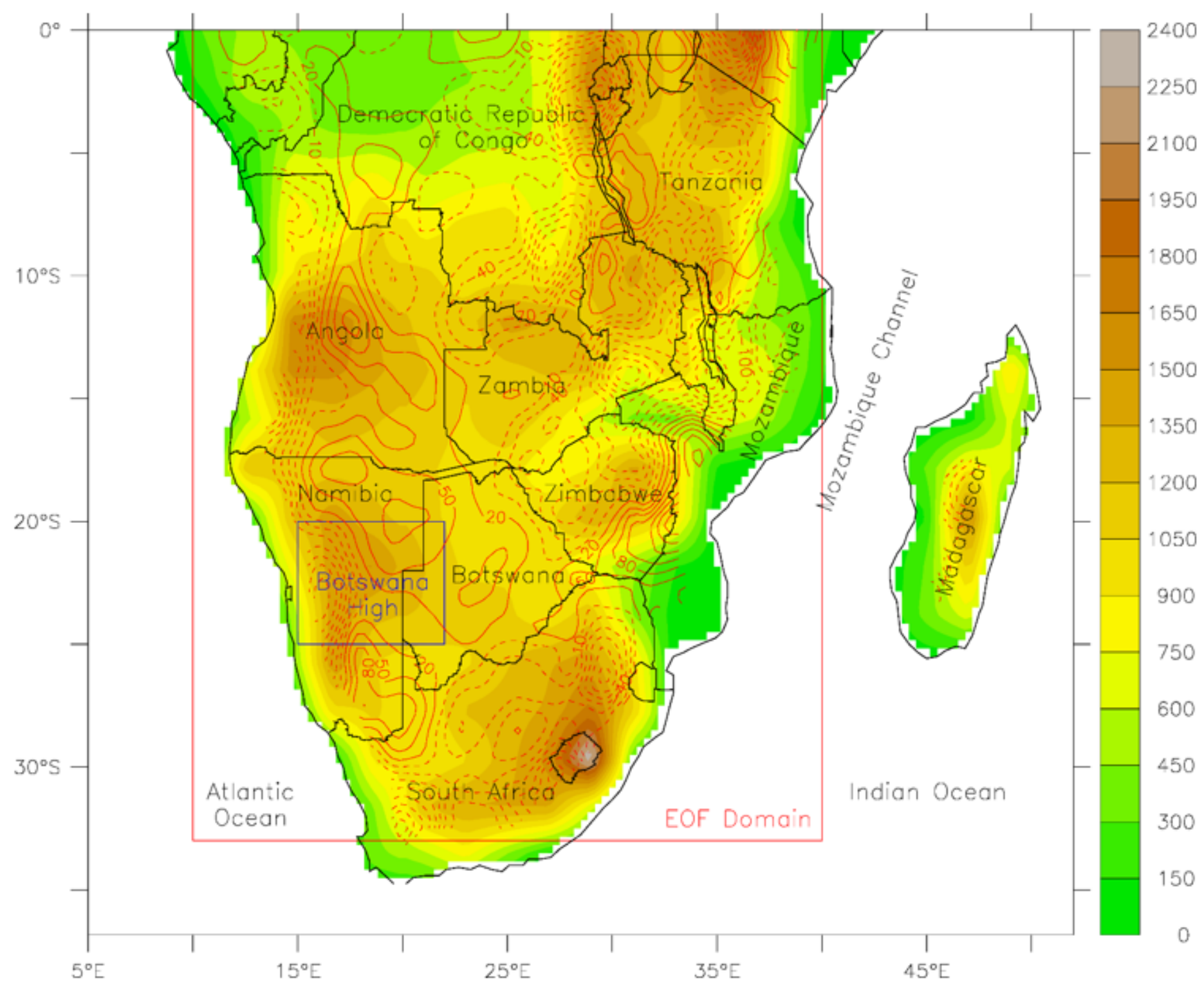

Figure 2

The southern African topography (in metres above sea level) as used in the MPAS model simulation. The contours show the biases (i.e. MPAS minus original topography) in the topography. The blue box shows the Botswana High core region (5o-22o E; $200-250 S)$, while the red box shows the EOF domain (10o-40o E; 0o-33oS) 
(a)

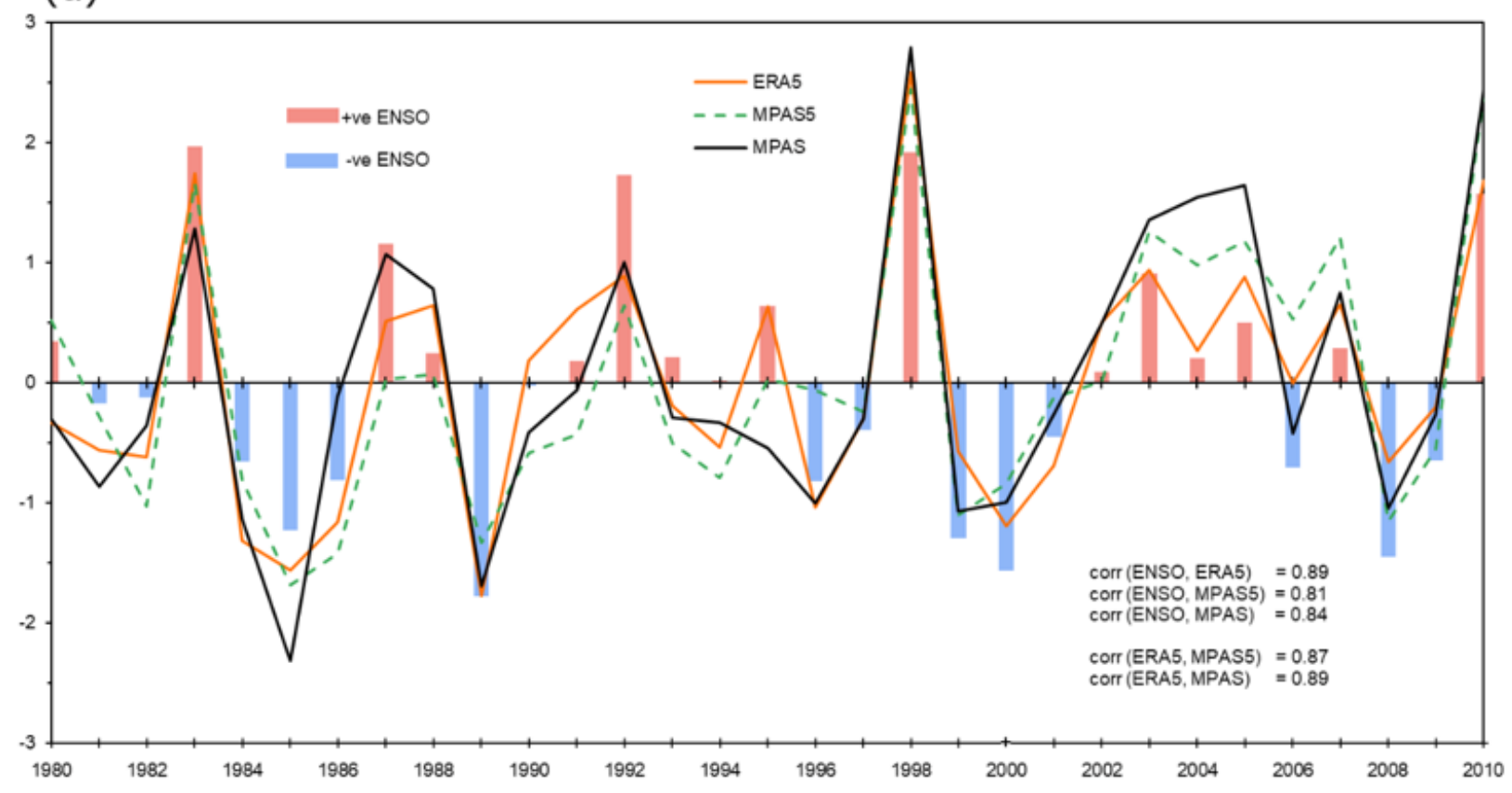

(b)

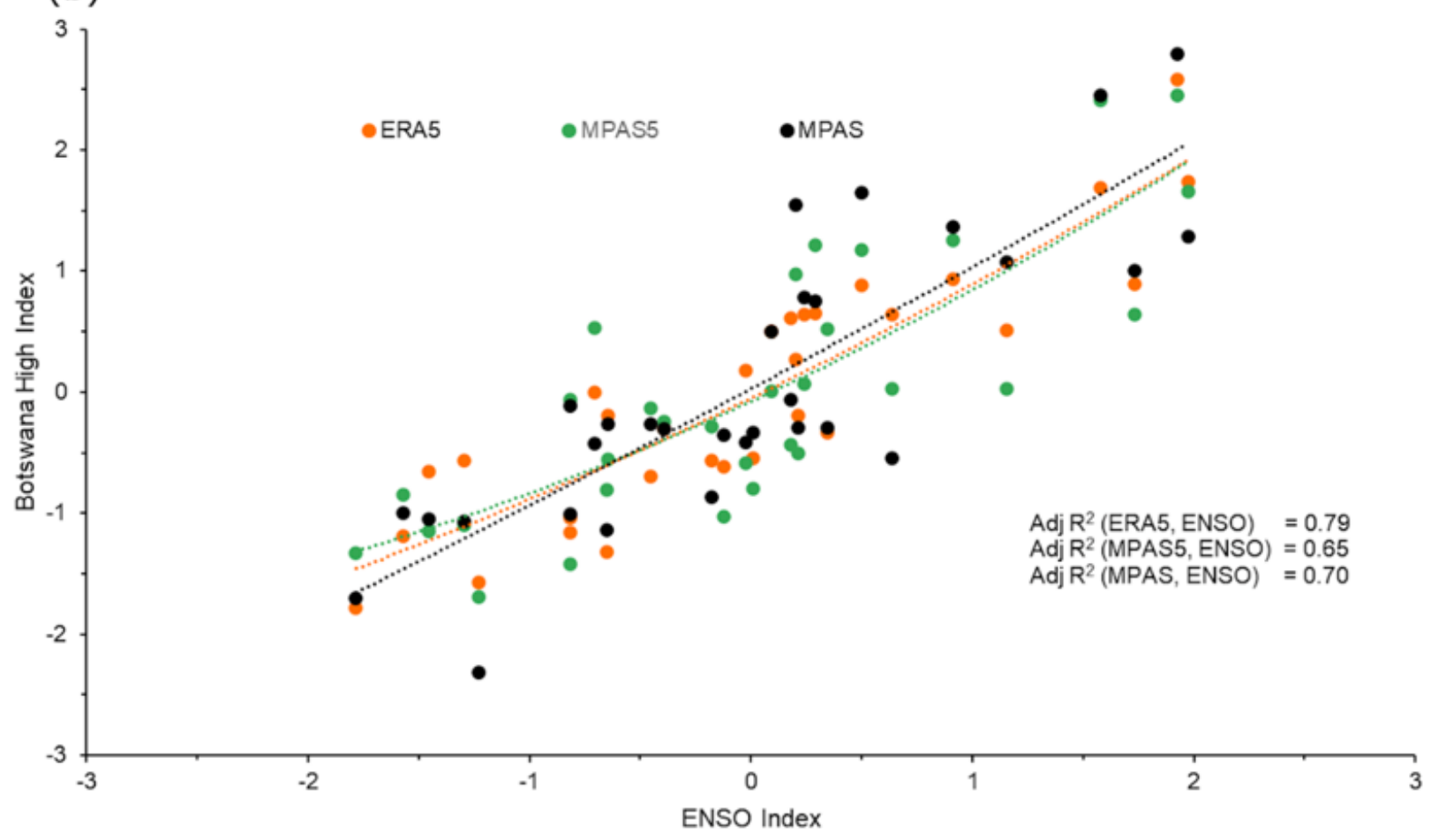

Figure 3

(a) Interannual variability of the Botswana High as depicted by ERA5, MPAS and MPAS5. The bars show the ENSO Index. The Botswana High indices are derived from the scores of EOF-1 of JFM $500 \mathrm{hPa}$ geopotential height over the study area $\left(10-14^{\circ} \mathrm{E}, 0-33^{\circ} \mathrm{S}\right)$ and the study period 1980-2010; (b) Scatter plot of the Botswana High Index (ERA5, MPAS and MPAS5) versus ENSO index for the same period. The lines represent the line of best fit, while $\mathrm{R} 2$ is the coefficient of determination 
E) Nino

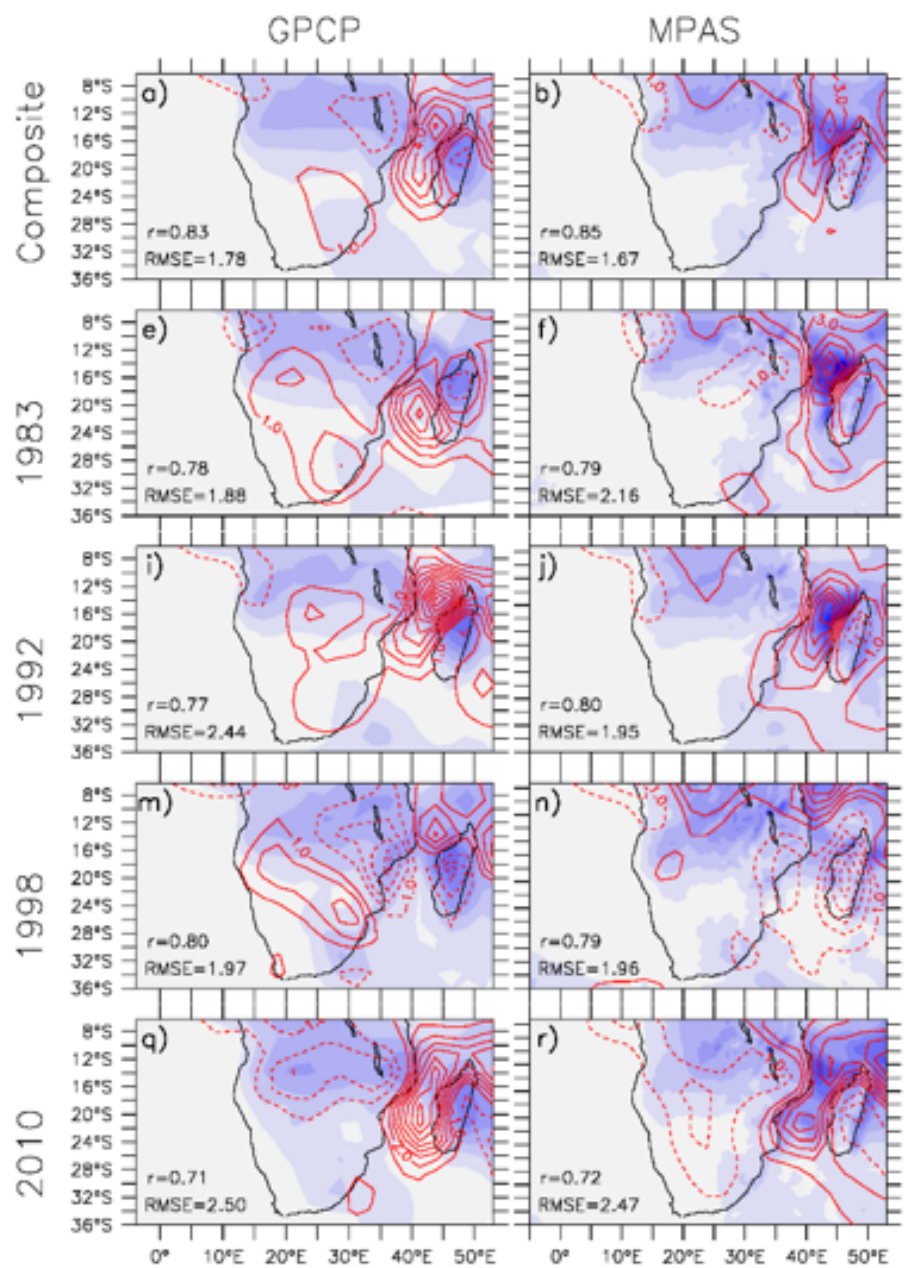

La Nina
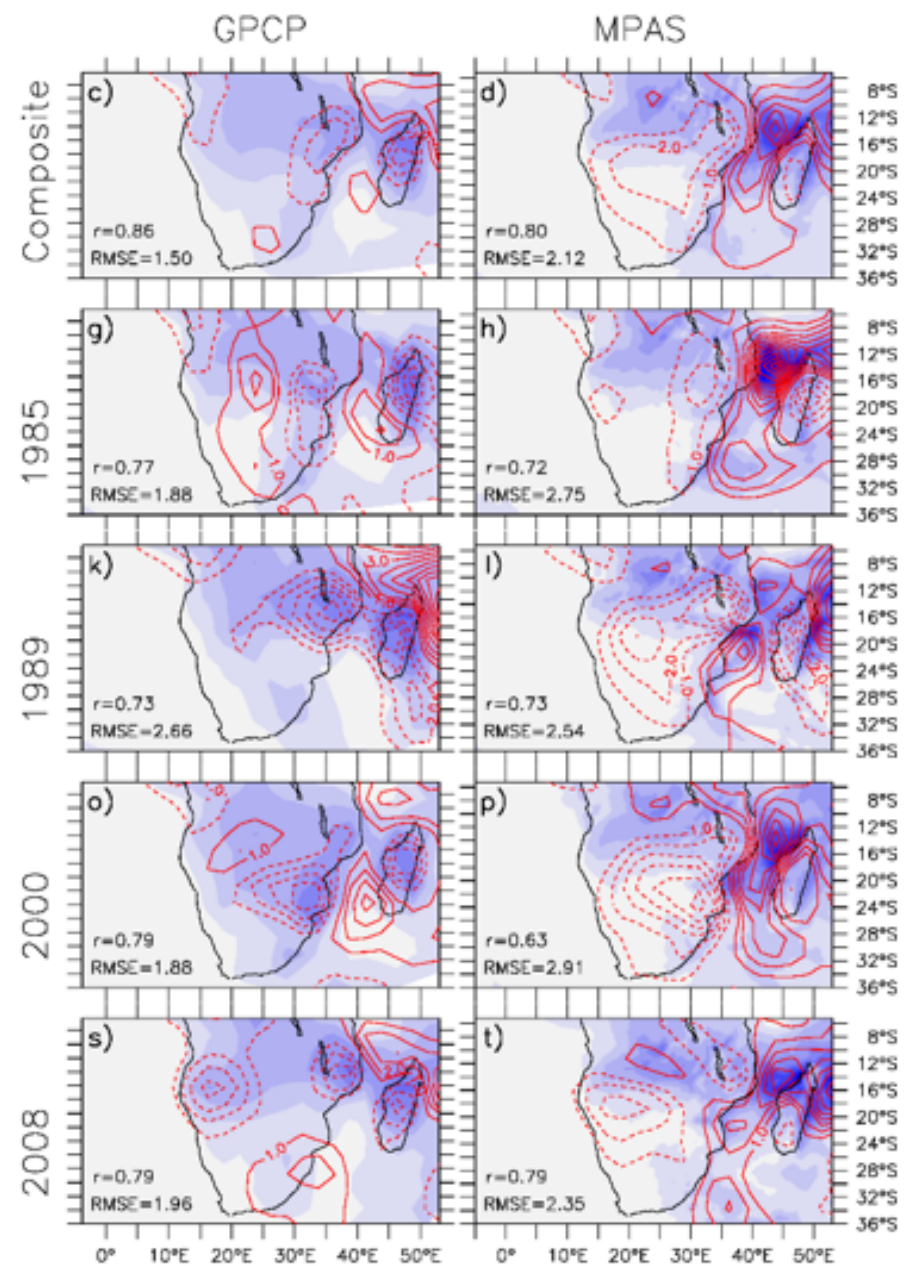

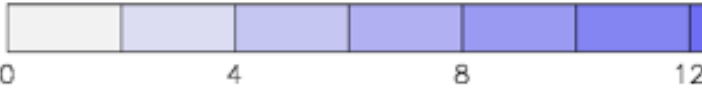

12

16

20

Figure 4

The spatial distribution of JFM rainfall ( $\mathrm{mm} /$ day; shaded) over southern Africa as depicted by GPCP and MPAS during the El Niño years (column 1 and 2) and La Niña years (column 3 and 4). The contours in the GPCP panels show the bias in the MPAS5 model simulation with reference to the GPCP (i.e. MPAS5 GPCP), while contours in the MPAS panels show the bias in the MPAS model simulation with reference to the GPCP (i.e., MPAS5 - GPCP). In the GPCP panels, the r-value represents the spatial correlation between GPCP and MPAS5 and RMSE represents the Root Mean Square Error. In the MPAS panels, the r-value represents the spatial correlation between GPCP and MPAS, and RMSE represents the Root Mean Square Error 
El Nino La Nina

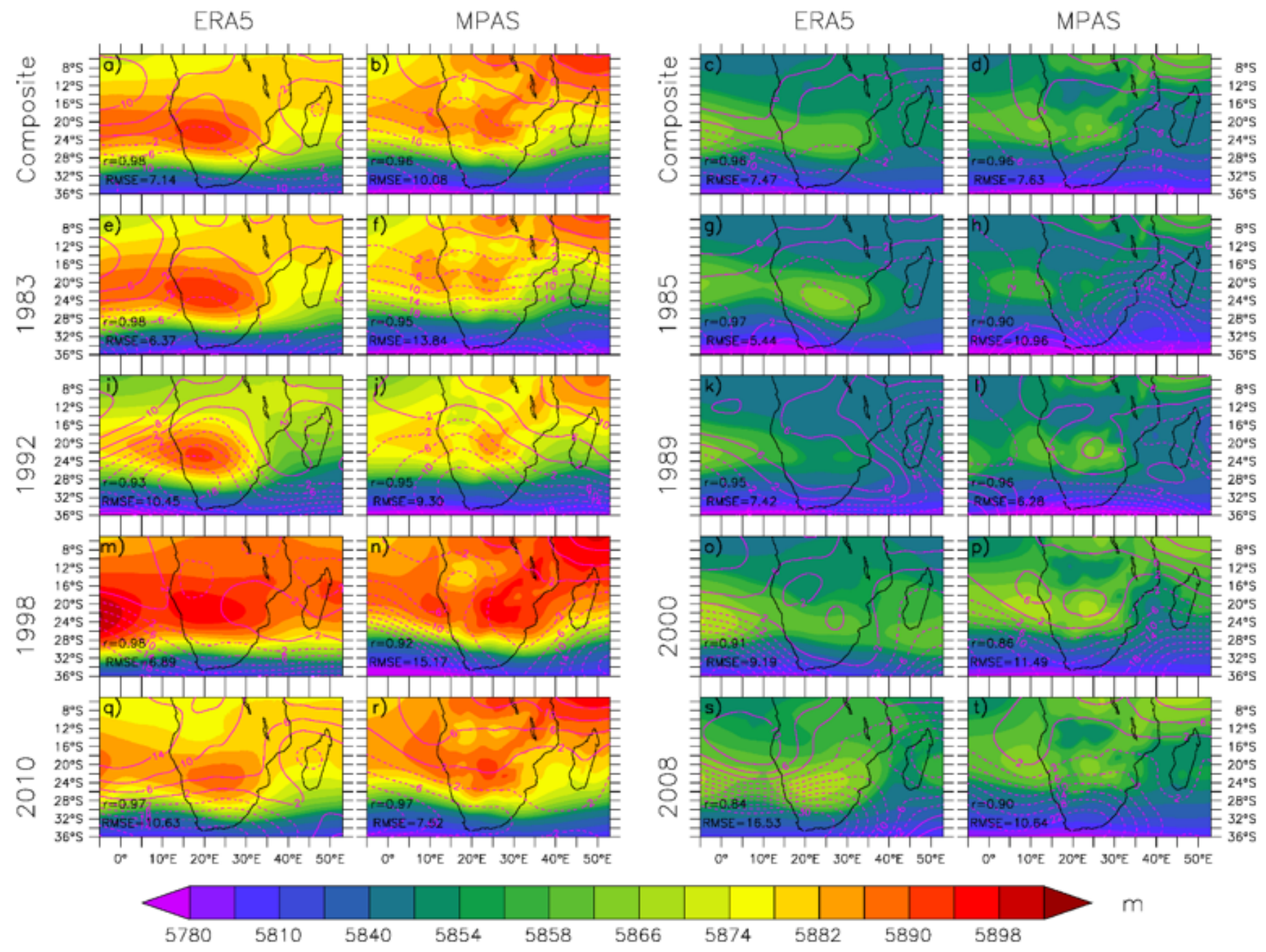

Figure 5

Same as Figure 4 but for JFM 500 hPa geopotential height 
(a) EOF Analysis

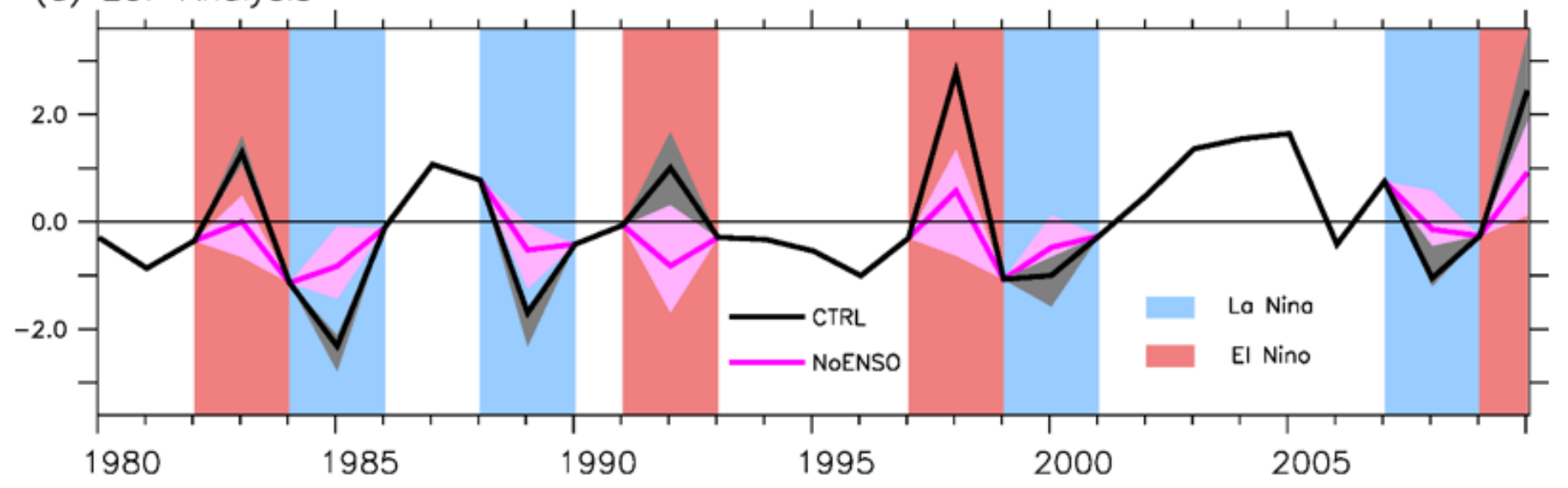

(b) Spatial Average

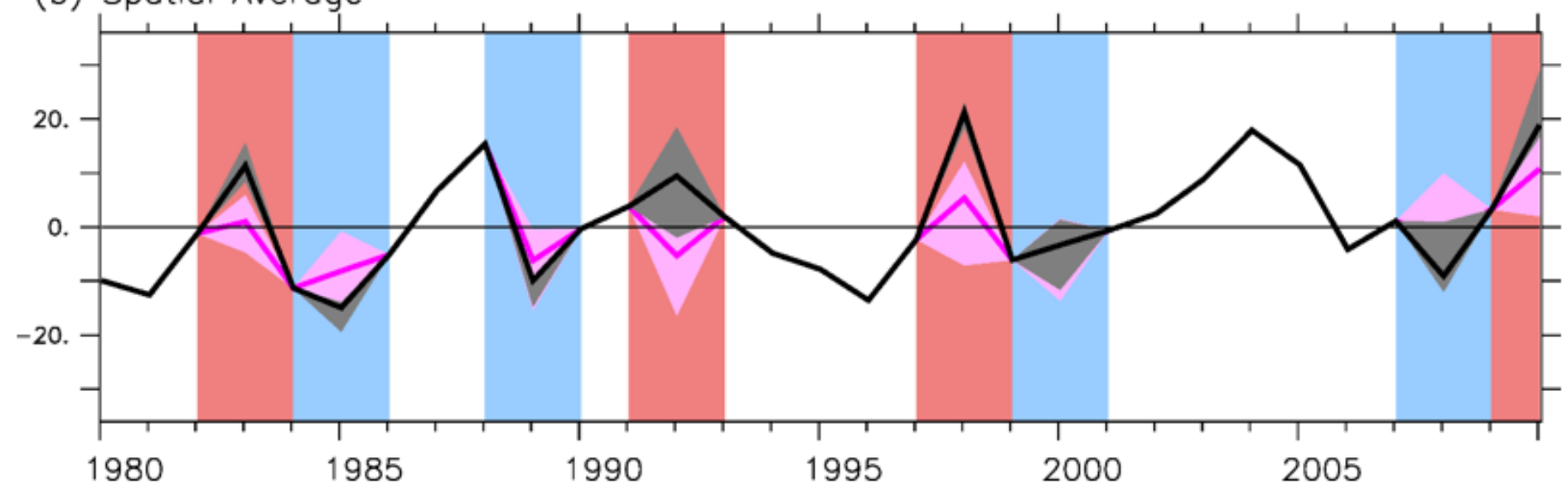

Figure 6

The interannual variability of the simulated Botswana High in the control (CTRL) and no ENSO (NoENSO) experiments. (a) The Botswana High index is derived from the score of EOF-1 of JFM $500 \mathrm{hPa}$ geopotential height over the study area $\left(10-14^{\circ} \mathrm{E}, 0-33^{\circ} \mathrm{S}\right)$. (b) The Botswana High index is derived from the spatial average of $500 \mathrm{hPa}$ over Botswana High core region (5o-22o E; $20 \mathrm{o}-25 \mathrm{oS}$ ) shown in Fig. 2. 

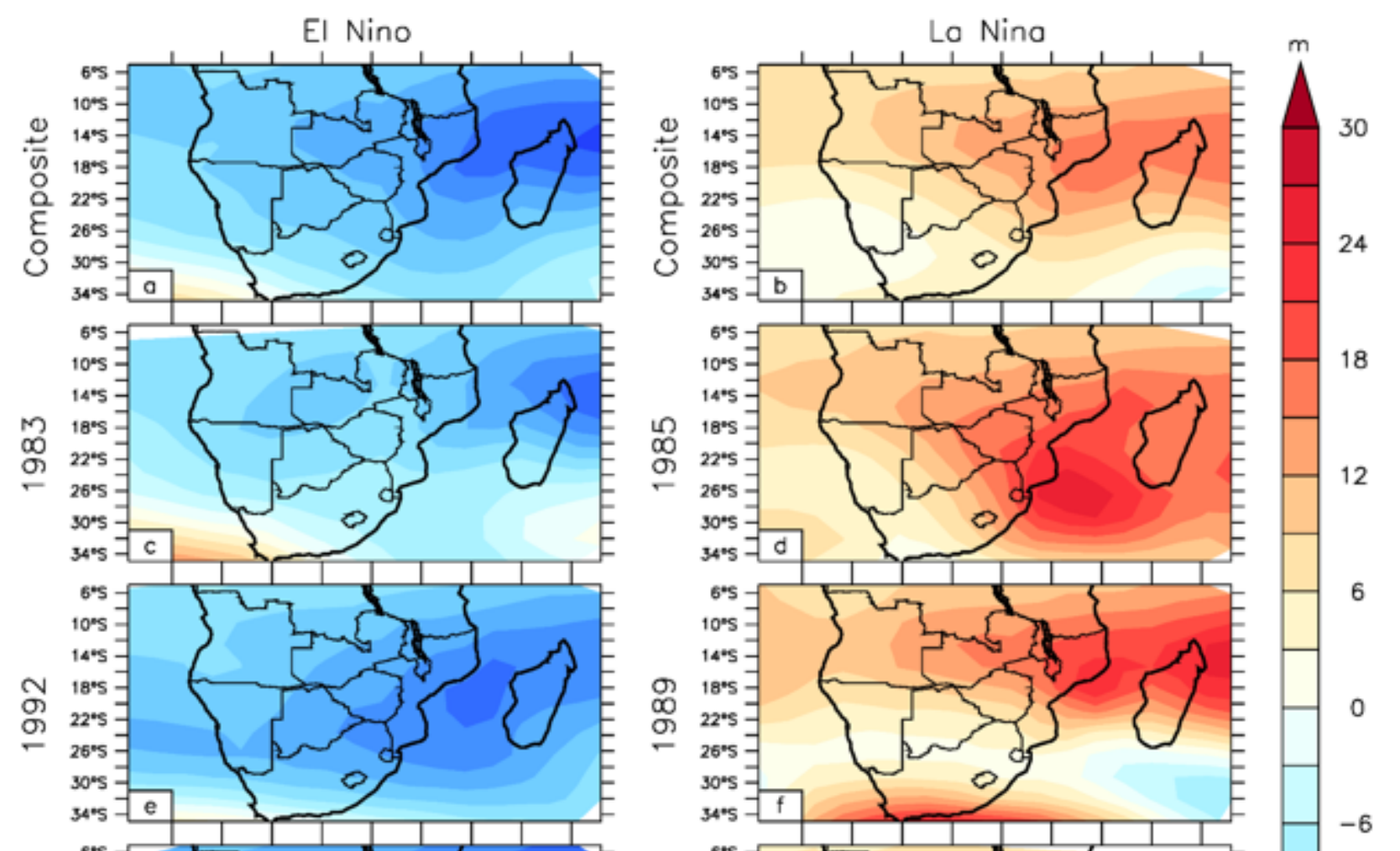

\section{0}
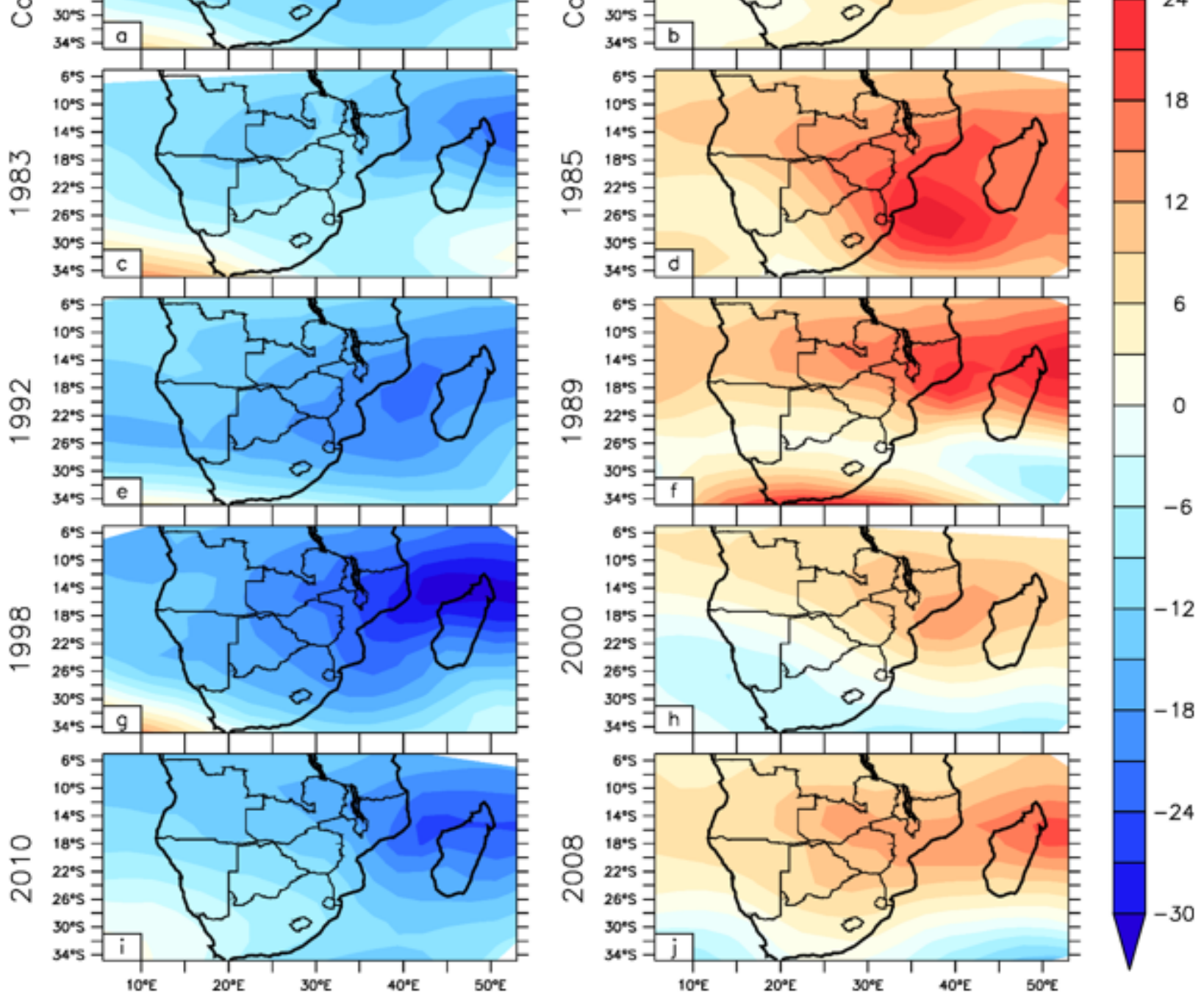

\section{Figure 7}

Impact of the removal of ENSO forcing (NoENSO minus CTRL) on the $500 \mathrm{hPa}$ geopotential height over southern Africa during El Niño and La Niña Years 
El Nino

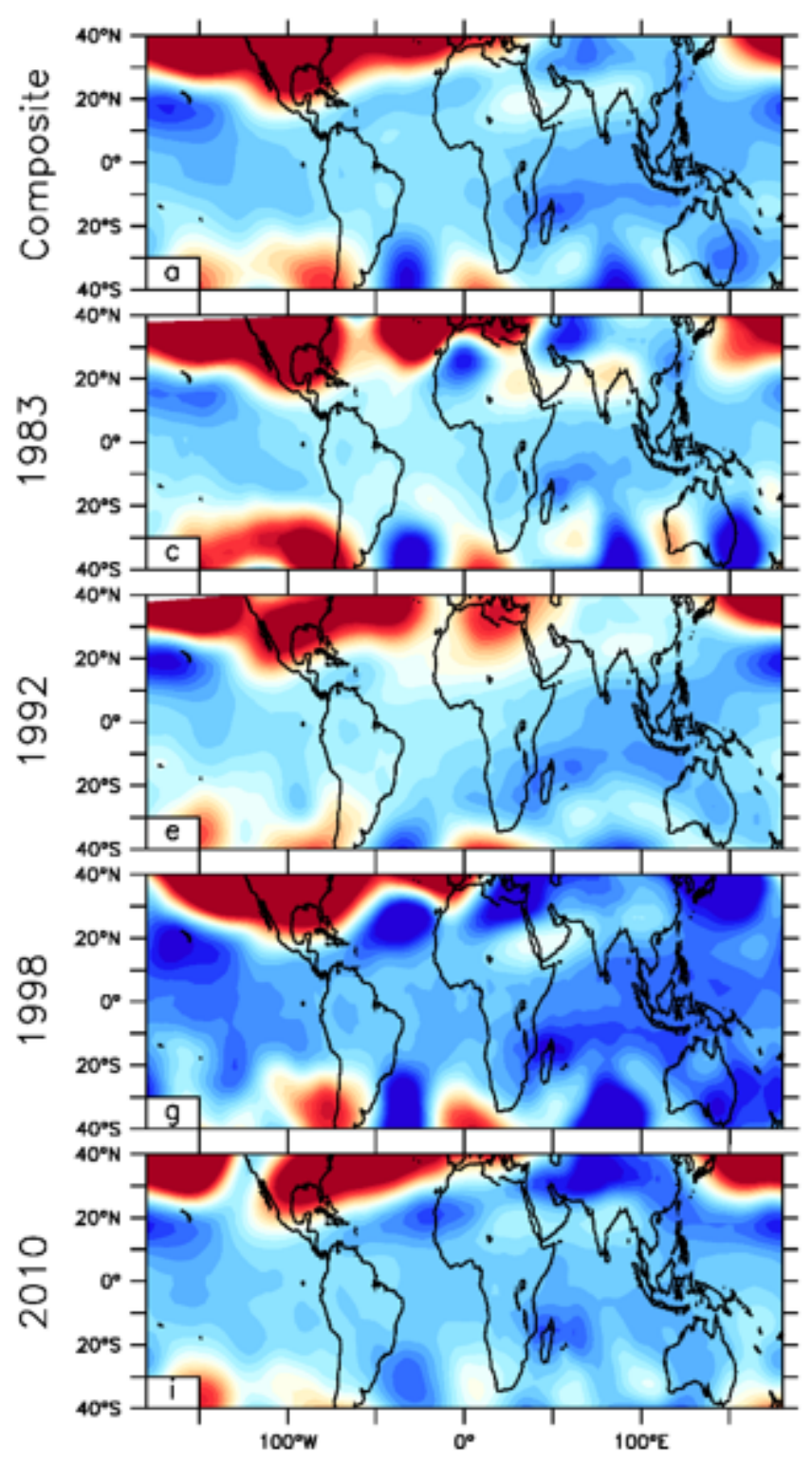

La Nina

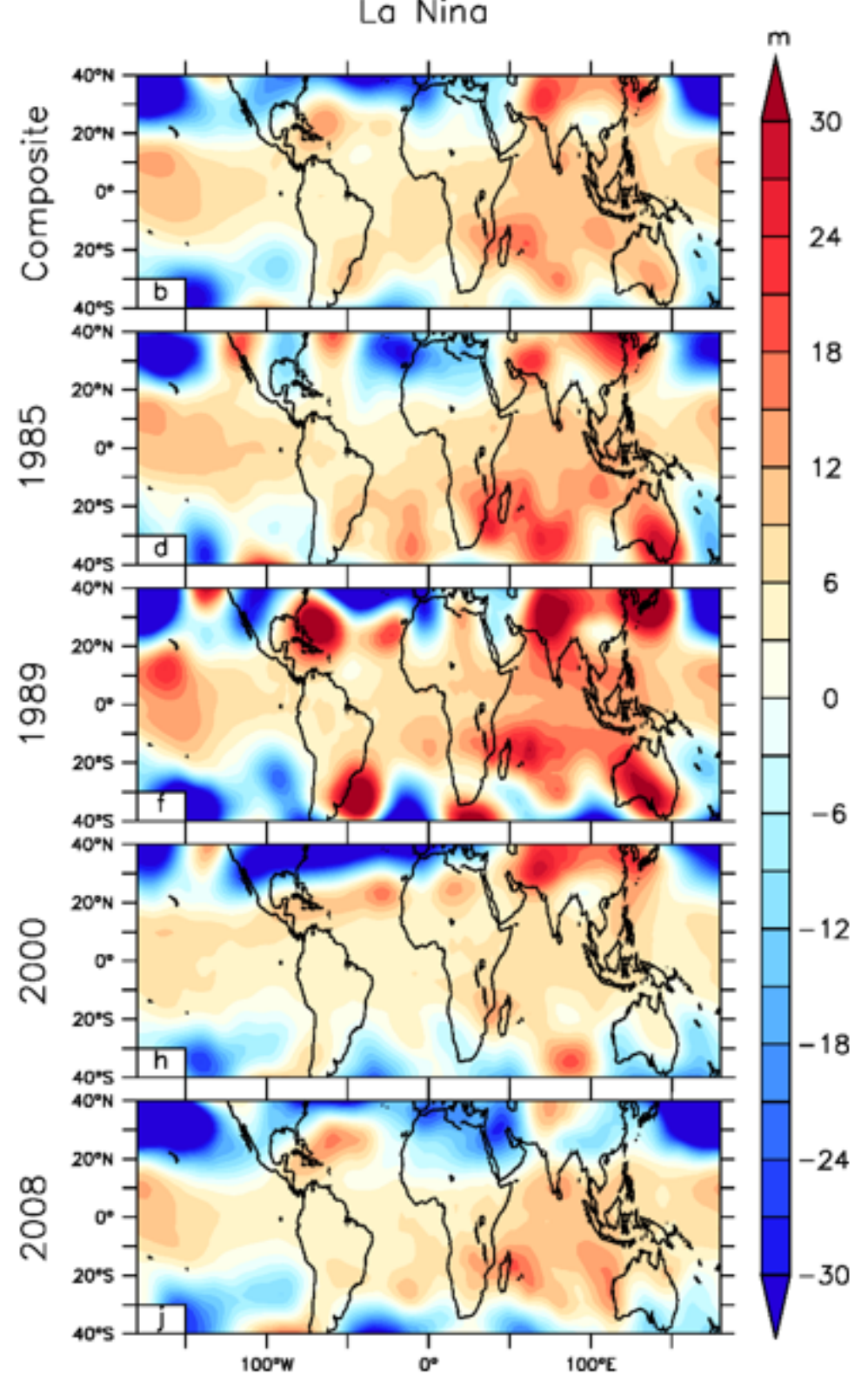

Figure 8

Impact of the removal of ENSO forcing (NoENSO minus CTRL) on the global 500 hPa geopotential height during El Niño and La Niña Years 
El Nino
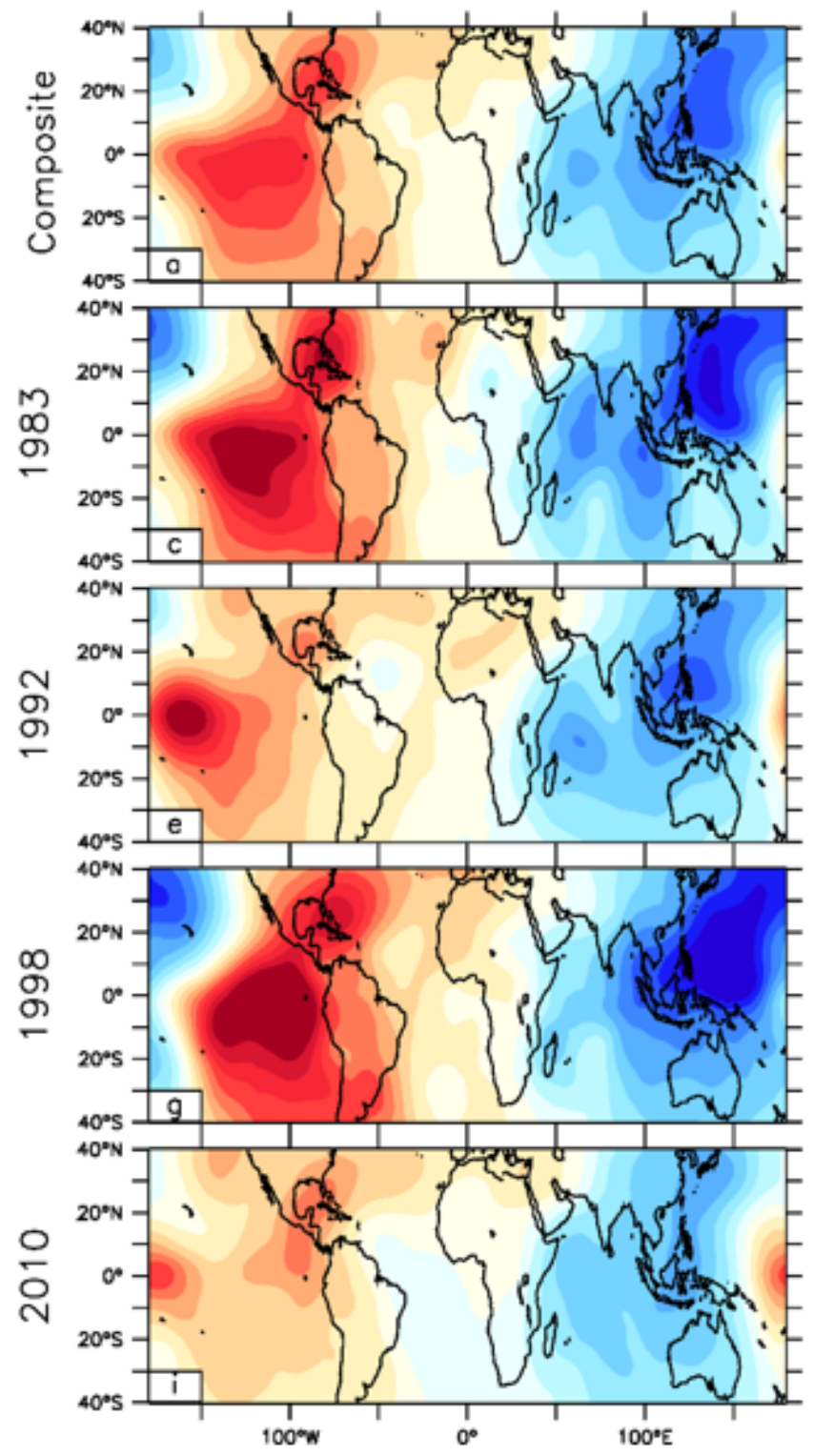

La Nina $\mathrm{m}^{2} \mathrm{~s}^{-1} \times 10^{6}$

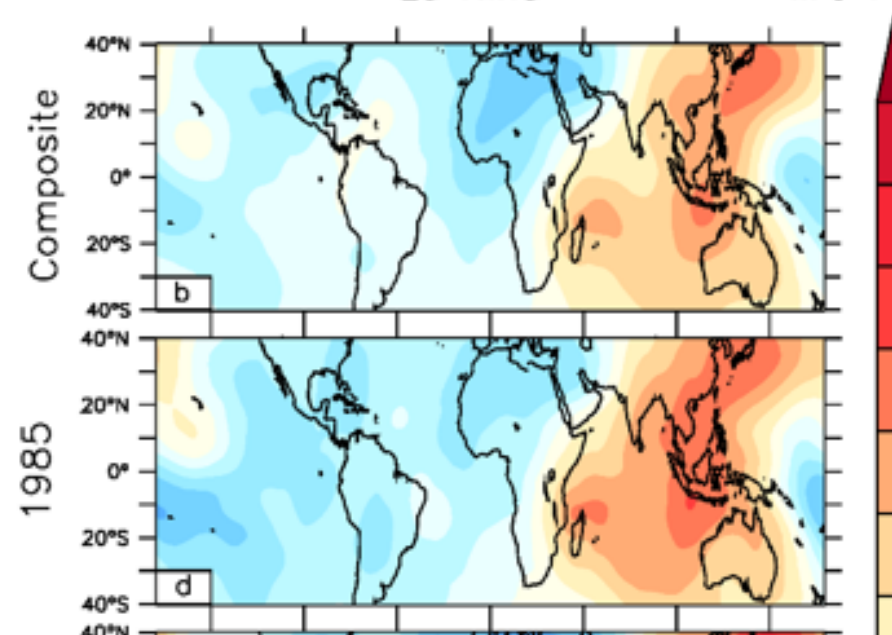

6

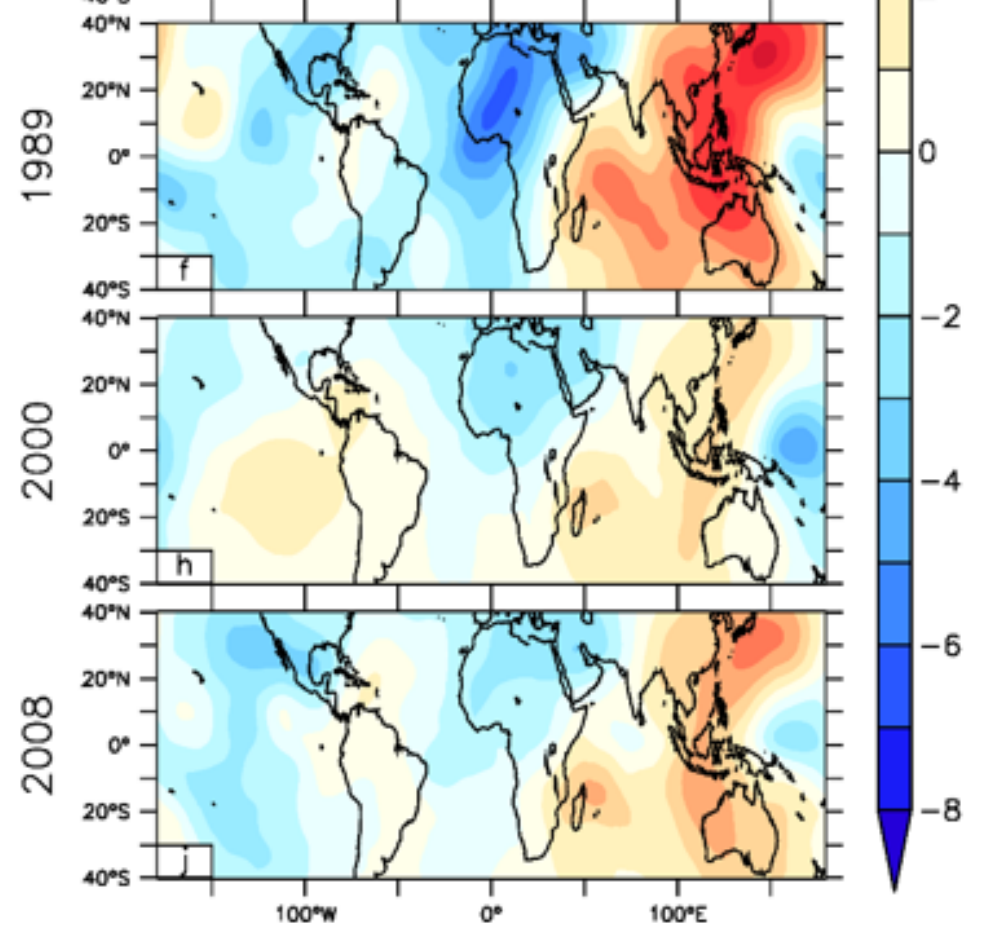

Figure 9

Same as Figure 8 but for 200 hPa Velocity Potential 
El Nino

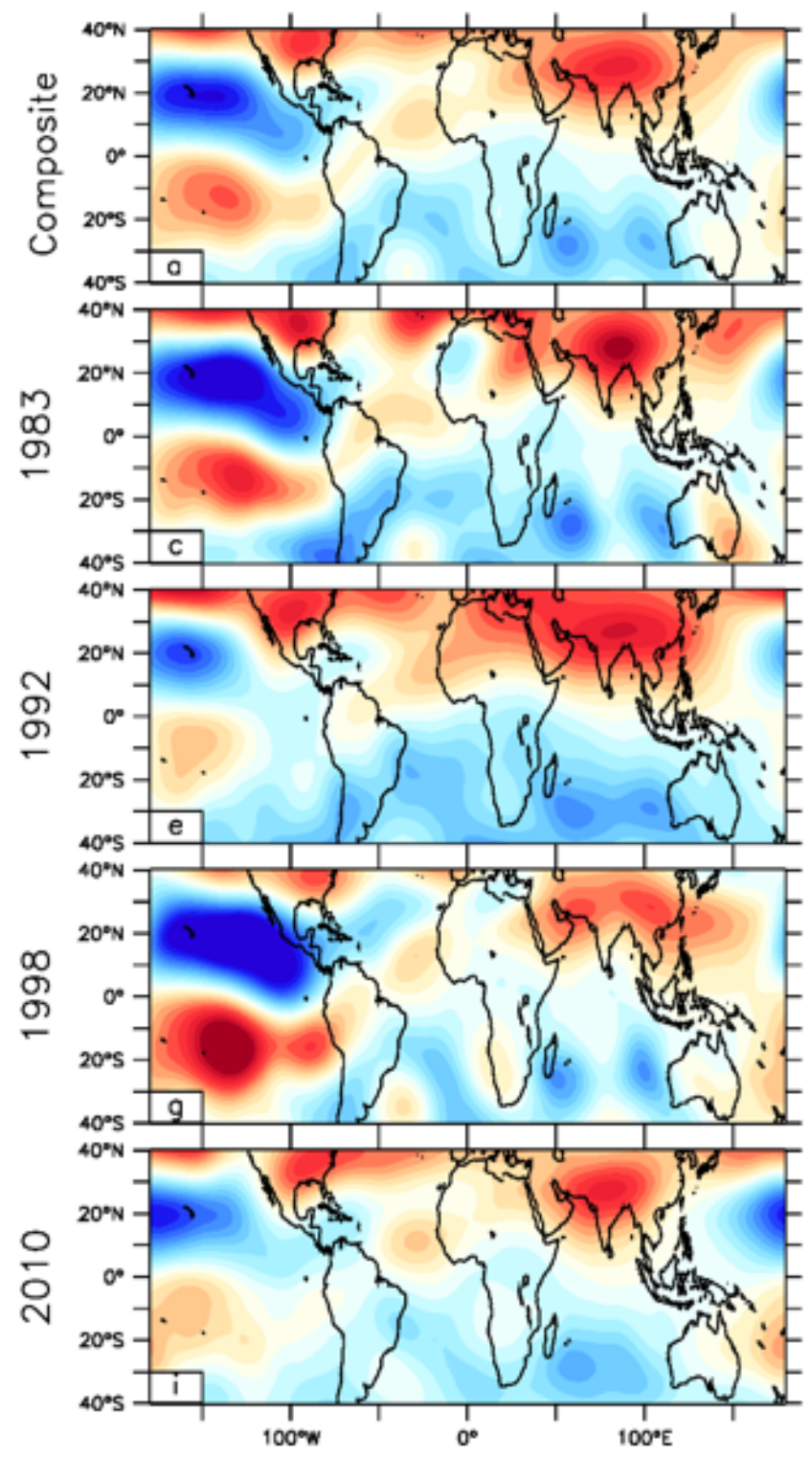

Lo Nina

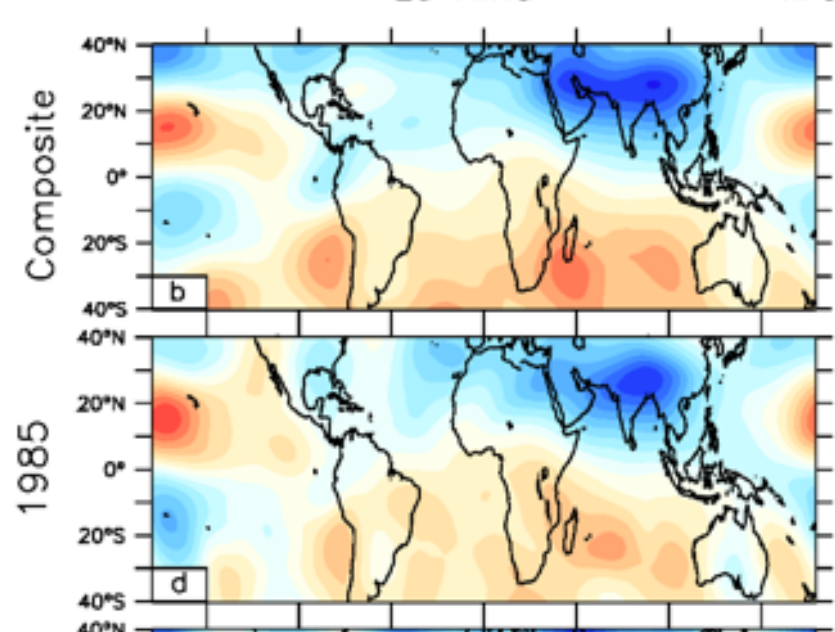

$\mathrm{m}^{2} \mathrm{~s}^{-1} \times 10^{6}$

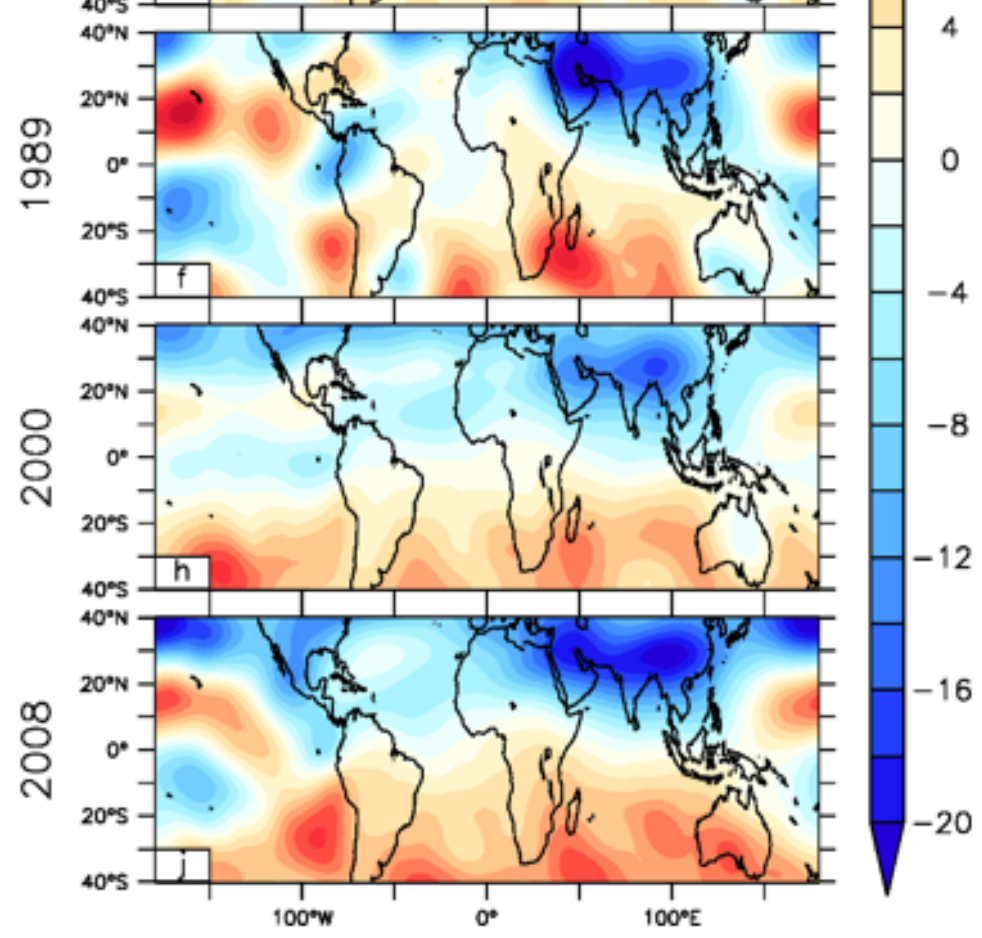

Figure 10

Same as Figure 8 but for 200 hPa Stream Function 